\title{
Non-Dimensional Modeling of the Effects of Weld Parameters on Peak Temperature and Cooling Rate in Friction Stir Welding
}

Bryan Jay Stringham

Brigham Young University

Follow this and additional works at: https://scholarsarchive.byu.edu/etd

Part of the Mechanical Engineering Commons

\section{BYU ScholarsArchive Citation}

Stringham, Bryan Jay, "Non-Dimensional Modeling of the Effects of Weld Parameters on Peak Temperature and Cooling Rate in Friction Stir Welding" (2017). All Theses and Dissertations. 6710.

https://scholarsarchive.byu.edu/etd/6710 
Non-Dimensional Modeling of the Effects of Weld Parameters on Peak Temperature and Cooling Rate in Friction Stir Welding

Bryan Jay Stringham

A thesis submitted to the faculty of

Brigham Young University

in partial fulfillment of the requirements for the degree of

Master of Science

Tracy W. Nelson, Chair

Carl D. Sorensen

Michael P. Miles

Department of Mechanical Engineering

Brigham Young University

Copyright (c) 2017 Bryan Jay Stringham

All Rights Reserved 


\author{
ABSTRACT \\ Non-Dimensional Modeling of the Effects of Weld Parameters on \\ Peak Temperature and Cooling Rate in Friction Stir Welding \\ Bryan Jay Stringham \\ Department of Mechanical Engineering, BYU \\ Master of Science
}

Methods for predicting weld properties based on welding parameters are needed in friction stir welding (FSW). FSW is a joining process in which the resulting properties depend on the thermal cycle of the weld. Buckingham's Pi theorem and heat transfer analysis was used to identify dimensionless parameters relevant to the FSW process. Experimental data from Al 7075 and HSLA-65 on five different backing plate materials and a wide range of travel speeds and weld powers was used to create a dimensionless, empirical model relating critical weld parameters to the peak temperature rise and cooling rate of the weld. The models created have R-squared values greater than 0.99 for both dimensionless peak temperature rise and cooling rate correlations. The model can be used to identify weld parameters needed to produce a desired peak temperature rise or cooling rate. The model can also be used to explore the relative effects of welding parameters on the weld thermal response.

Keywords: Friction Stir Welding, Dimensional Analysis, Non-Dimensionalization, Thermal Response Modeling, Peak Temperature, Cooling Rate, Rosenthal equation, Critical Setup and Operating Weld Parameters, Experimental Data 


\section{ACKNOWLEDGMENTS}

I am grateful for and indebted to the following individuals who have made this work possible in personal and academic ways:

My parents, Mark and Kathy Stringham, who taught me a strong work ethic and encouraged my best work in all I do.

The late Chris Coray whose example, kindness, and mentoring encouraged my academic ambition and helped lay the mathematical foundation for my ability to perform this work.

My wife, Tiffany, whose encouragement and support has been unfailing and instrumental in helping me persist to this work's completion.

My advisors and mentors, Dr. Tracy Nelson and Dr. Carl Sorensen, who have provided invaluable direction and sacrificed many hours in my behalf to help me develop this work into its resultant useful form.

Much-appreciated financial support for this work was provided by the National Science Foundation (NSF)-funded Center for Friction Stir Processing and a NSF Graduate Research Fellowship under Grant No. 1247046 (Any opinions, findings, and conclusions or recommendations expressed in this material are those of the author(s) and do not necessarily reflect the views of the National Science Foundation). 


\section{TABLE OF CONTENTS}

LIST OF TABLES $\ldots \ldots \ldots \ldots \ldots \ldots \ldots \ldots \ldots \ldots \ldots$

LIST OF FIGURES $\ldots \ldots \ldots \ldots \ldots \ldots \ldots \ldots \ldots \ldots$ vi

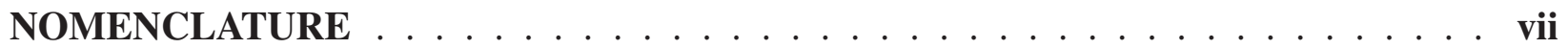

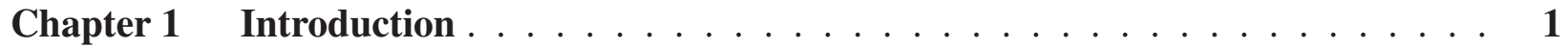

Chapter 2 Methods . . . . . . . . . . . . . . . . . . . 6

2.1 Experimental Data . . . . . . . . . . . . . . . . . . 6

2.2 Modeling Approach . . . . . . . . . . . . . . . . . . . 8

2.2.1 Derivation of Non-Dimensional Parameters . . . . . . . . . . . . . 8

2.2.2 Creation of Non-Dimensional Empirical Model . . . . . . . . . . . . . . 10

Chapter 3 Results and Discussion . . . . . . . . . . . . . . . . . . . 12

3.1 Non-Dimensional Empirical Model . . . . . . . . . . . . . . . . . . . . . . 12

3.2 Application of Model . . . . . . . . . . . . . . . . . . . . . . . . . . . . . 14

3.2.1 Estimation of Weld Power . . . . . . . . . . . . . . . . . . . . . 14

3.2.2 Parameter Control for Desired Cooling Rate . . . . . . . . . . . . . . . . 16

3.2.3 Relative Importance of Weld Parameters . . . . . . . . . . . . . . . . . 17

Chapter 4 Conclusions $\ldots \ldots \ldots \ldots \ldots \ldots \ldots \ldots$

Chapter 5 Future Work . . . . . . . . . . . . . . . . . . . . . . . . . 24

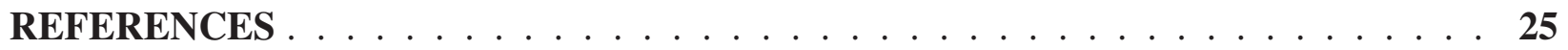

Appendix A Tool Drawings $\ldots \ldots \ldots \ldots \ldots \ldots$

Appendix B Temperature vs. Time Plots . . . . . . . . . . . . . . . 31

Appendix C Raw Experimental Parameter Data . . . . . . . . . . . . . 33 


\section{LIST OF TABLES}

1.1 Summary of literature showing diverse approaches to determining the effect of FSW parameters on post-weld properties. . . . . . . . . . . . . 2

2.1 Thicknesses and properties of materials used in this study. . . . . . . . . . . 7

2.2 Critical parameters and their units used in non-dimensional modeling of FSW. . . . . . 9

C.1 Experimental parameters and temperature data used to create the models. . . . . . . 34 


\section{LIST OF FIGURES}

1.1 Diagram illustrating how welding parameters can be related to weld mechanical properties via a thermal response model. . . . . . . . . . . . . . . . . . . 5

1.2 Volumetric heat flow relative to the weld nugget during friction stir welding. Assumptions: Weld has reached steady state, plate width is semi-infinite, $Q_{\text {conv } / \text { rad }}<<Q_{\text {cond }}$, no heat transfer occurs between the backing plate and the anvil beneath it, $Q_{\text {out tool }}$ is small. . . . . . . . . . . . . . . . . . . . . . . . 5

3.1 Log-scale correlations between fit versus measured dimensionless peak temperature rise (a) and dimensionless cooling rate (b) . . . . . . . . . . . . . . . . 12

3.2 Log-scale correlation between fit and measured peak temperature rise (a) and cooling

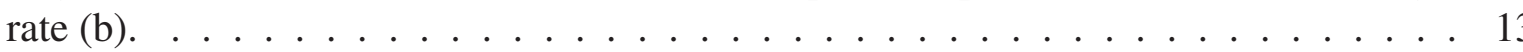

3.3 Ratio of predicted to actual power versus thermocouple distance $R_{0}$ from weld center at the top of the workpiece where $R_{0}=\sqrt{y^{2}+z^{2}}$ for each thermocouple location. . . 15

3.4 Predicted travel speed versus backing plate thermal diffusivity for a given cooling rate created according to the model. Vertical dotted lines represent thermal diffusivities of various backing plates (from left to right): Granite, AL6XN, 1018 Steel, A16061, 99 $\%$ Pure Copper. . . . . . . . . . . . . . . . . . . . . . . . . . . . . . . . 17

3.5 Effects of different $v$ and $\alpha_{b p}$ parameter ranges on $\theta$ and $\beta$ according to model. Parameter range 1 (denoted by a curves made of a solid line with unfilled markers) corresponds to a range of $v=0.83-2.5 \mathrm{~mm} / \mathrm{s}$ and $\alpha_{b p}=2.3-13 \mathrm{~mm}^{2} / \mathrm{s}$. Parameter range 2 (denoted by curves made of a dash-dot line with filled markers) corresponds to a range of $v=2.5-4.17 \mathrm{~mm} / \mathrm{s}$ and $\alpha_{b p}=2.3-114 \mathrm{~mm}^{2} / \mathrm{s}$.

Other parameters held constant constant (WP material: Al 7075; WP thickness: 9.53 $\mathrm{mm}$; BP thickness: $6.35 \mathrm{~mm}$; weld power: $2400 \mathrm{~W}$ ) Vertical dotted lines correspond to parameter range 1 ; vertical dashed lines correspond to parameter range $2 . \ldots . .19$

3.6 Relative importance of $\alpha_{b p}$ and $v$ for two different ranges of weld peak temperature rise and cooling rate (model) and weld properties (experimental). $\Delta_{f\left(\alpha_{b p}\right)} / \Delta_{f(v)}>1$ indicates that $\alpha_{b p}$ is of greater relative importance in determining the resulting properties whereas $\Delta_{f\left(\alpha_{b p}\right)} / \Delta_{f(v)}<1$ indicates that $v$ is of greater relative importance. . . . . . 21

A.1 PCBN CS4 tool, model E44111. . . . . . . . . . . . . . . . . . . . . . 29

A.2 H13 CS4 tool used in Al 7075-T7351 experiments. . . . . . . . . . . . . . . . 30

B.1 Example plot for calculation of $\theta$ and $\beta$ from a temperature vs. time profile from the HSLA-65 experiment. Parameters used correspond to Data Set ID 112 as shown in Appendix C. . . . . . . . . . . . . . . . . . . . . . . 31

B.2 Example plot for calculation of $\theta$ and $\beta$ from a temperature vs. time profile from the Al 7075 experiment. Parameters used correspond to Data Set ID 60 as shown in Appendix C . . . . . . . . . . . . . . . . . . . . . 32 


\section{NOMENCLATURE}

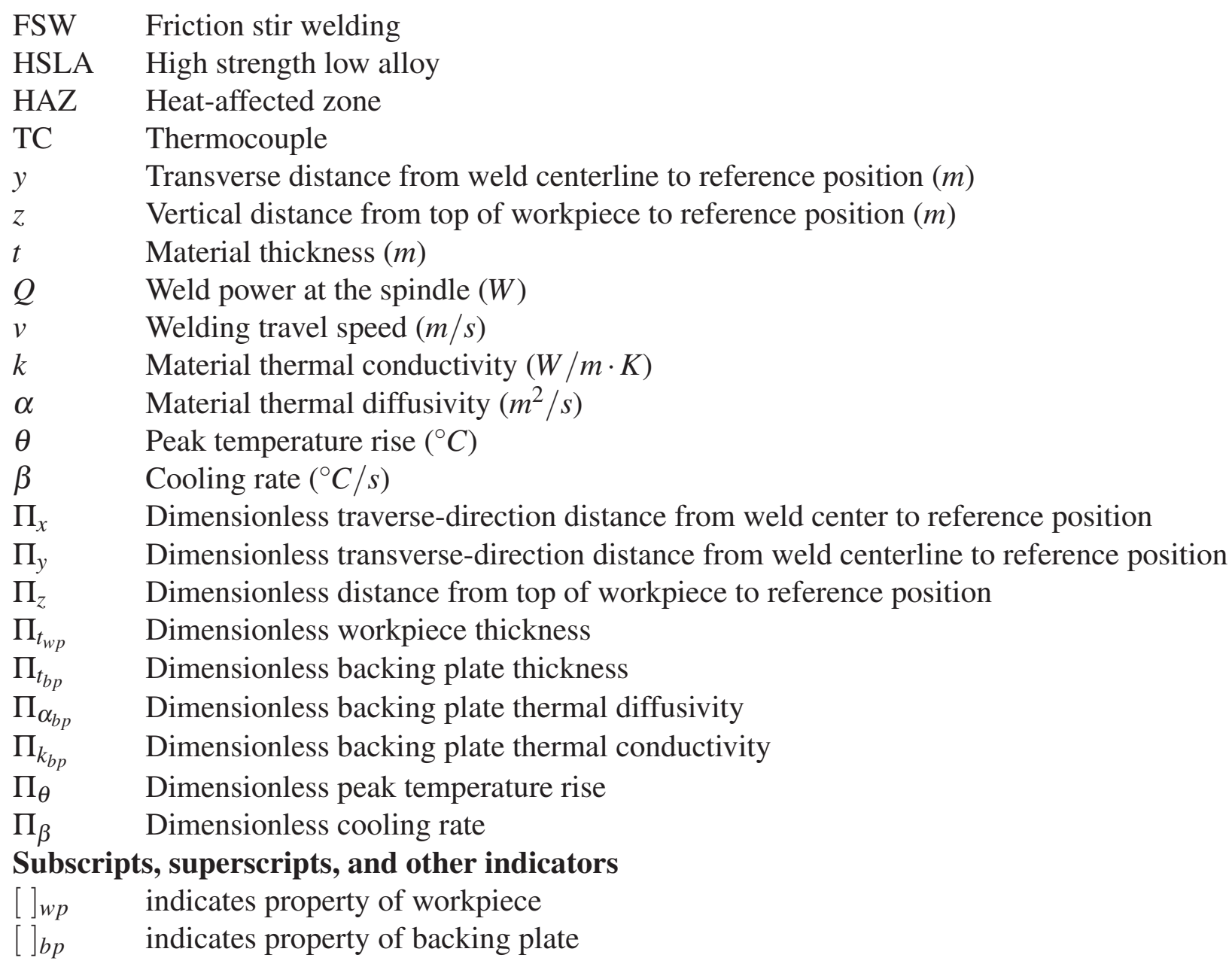




\section{CHAPTER 1. INTRODUCTION}

Friction stir welding (FSW) is a solid-state joining process that has increased in utilization since its invention at The Welding Institute in 1991 [1]. FSW uses a high speed rotating tool to plastically deform and "stir" the joint together at temperatures below the melting point of the material.

Applications for FSW are increasing due to its ability to produce joints with mechanical properties often superior to those created by other welding or joining processes. Methods of predicting mechanical properties based on welding parameters are needed to reliably create desirable welds and maximize the usefulness of FSW.

The most common approach to predicting weld properties has been to correlate these directly with welding parameters. Table 1.1 shows only a small sampling of the approaches taken to relate various weld parameters with a variety of post-weld properties [2-22].

The Primary Operational parameters are the parameters that can be adjusted at the machine level to vary the process. Secondary Operational parameters are the parameters that can be used to describe the FSW process but are fundamentally outputs of the primary operational and setup parameters. These can also be used to control the FSW process by varying one or more primary control parameters to achieve a desired parameter value. The Setup parameters include the workpiece (WP) material and geometry, the backing plate (BP) material and geometry, and the tool material and design. Other unlisted setup parameters which are seldom considered include the clamping force on the workpiece and the stiffness of the FSW machine. The Thermal Response includes the peak temperature and cooling rate near the weld which can be used to characterize the weld heat transfer process. The Physical Property Response variables include the physical or microstructural properties which result from the welding process. 


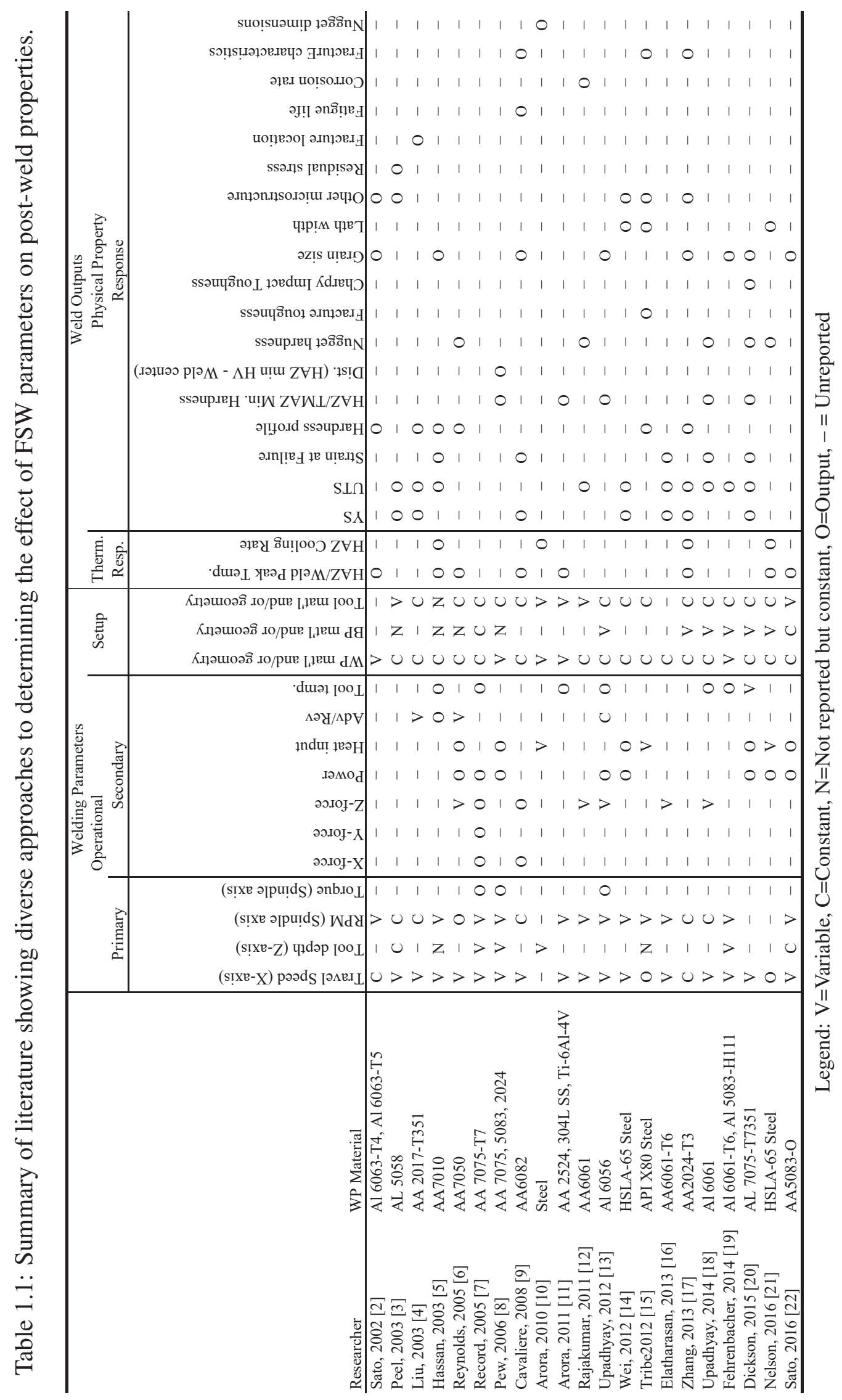


The inconsistency in specific materials, parameters, and properties considered in these studies have resulted in models and conclusions that are generally only valid for the material and setup studied.

An alternative approach to correlating welding parameters directly with weld properties is to use a heat transfer approach to first correlate welding parameters with the welding process thermal cycle, or peak temperature rise and cooling rate. Information from CCT diagrams and other thermophysical and kinetics models may then be used to predict weld properties via known relationships between thermal cycles and the associated microstructural transformation. The viability of this alternative approach in FSW is supported by the strong dependencies many have found between the welding process thermal cycle and resulting weld properties [3,5,10,11,13,19,21,23-27]. However, the heat transfer approach is rarely considered as shown by the Thermal Response columns in Table 1.1. The primary benefit of models created using the heat transfer approach is that they would be applicable to any material and experiment for which material properties and critical welding parameters are known.

Figure 1.1 summarizes the two different approaches. Previous parameter-to-property studies (indicated by dashed lines) have correlated both primary and secondary operational parameters directly with weld properties but have still not resulted in widely applicable models.

One challenge of the heat transfer approach is identifying which of the many parameters fundamentally relate to the heat transfer of the process. Rosenthal identified the critical parameters for heat transfer in arc welding [28,29]. His equations describe temperature rise $\theta$ as a function of position for 3-D heat transfer and a moving heat source in a semi-infinite (Eq. 1.1) and a thick (Eq. 1.2) plate:

$$
\begin{gathered}
\theta=\frac{Q}{2 \pi k_{w p}}\left(\frac{1}{R}\right) \exp \left[-\frac{v}{2 \alpha_{w p}}(R+x)\right] \\
\theta=\frac{Q}{2 \pi k_{w p}} \exp \left(-\frac{v x}{2 \alpha_{w p}}\right) \times\left[\sum_{i=-\infty}^{i=\infty} \frac{1}{R_{i}} \exp \left(-\frac{v}{2 \alpha_{w p}} R_{i}\right)\right]
\end{gathered}
$$

where $x, y$, and $z$ are the distances from the center of the heat source to the location of interest in the traverse, transverse-horizontal, and transverse-vertical directions, respectively. $R=\sqrt{x^{2}+y^{2}+z^{2}}$, $R_{i}=\sqrt{x^{2}+y^{2}+\left(z-2 i t_{w p}\right)^{2}}, Q$ is the weld power, $v$ is the weld travel speed, $k_{w p}$ is the workpiece thermal conductivity, $\alpha_{w p}$ is the workpiece thermal diffusivity, and $t_{w p}$ is the workpiece thickness. 
Rosenthal's equations apply only to conventional welding but help identify parameters which are equally relevant in FSW.

Neither of Rosenthal's equations considers the heat transfer effects of a backing plate which are generally used during FSW. Previous studies $[13,18,19,21]$ and the FSW setup heat transfer diagram (Figure 1.2) further identify backing plate thickness $\left(t_{b p}\right)$ and thermal properties $\left(\alpha_{b p}\right.$ and $k_{b p}$ ) as critical parameters in the FSW heat transfer process.

Rosenthal's equations, previous studies, and the FSW heat transfer diagram identify $v$ and $Q$ as the critical operational parameters and $t_{w p}, t_{b p}, \alpha_{w p}, \alpha_{b p}, k_{w p}$, and $k_{b p}$ as the critical setup parameters that govern heat transfer through the workpiece in FSW. $y$ and $z$ distance are the critical position parameters for identifying the peak temperature at a given location in the heat-affected zone (HAZ) for steady state welds. Assuming stir zone deformation produces a void-free weld and complete stir zone recrystallization, the post-weld properties will depend entirely upon these parameters.

Other welding parameters correlate with the critical heat transfer parameters but do not fundamentally affect welding heat transfer. RPM, the most commonly reported parameter other than travel speed, affects weld power since weld power is the product of RPM and torque. Z-force has also been shown to correlate strongly with weld power [13]. The heat transfer effects of RPM, Z-force, and other parameters on the heat transfer in the welding process are effectively captured by $Q$.

Some of the heat transfer critical operating and setup parameters are often overlooked when studies are reported. Only 8 of 21 studies listed in Table 1.1 even report weld power, and only 8 of the 21 studies report backing plate. Widely applicable models relating the critical FSW heat transfer parameters to the thermal cycle of the welding process are needed but do not exist.

The objective of this study was to create a model that predicts the peak temperature rise and cooling rate in the weld as a function of position and the critical heat transfer parameters. The model was then applied to various other studies to show how it can be used to assist in the selection of welding parameters and explain inconsistencies between existing conclusions regarding the role of FSW parameters. 


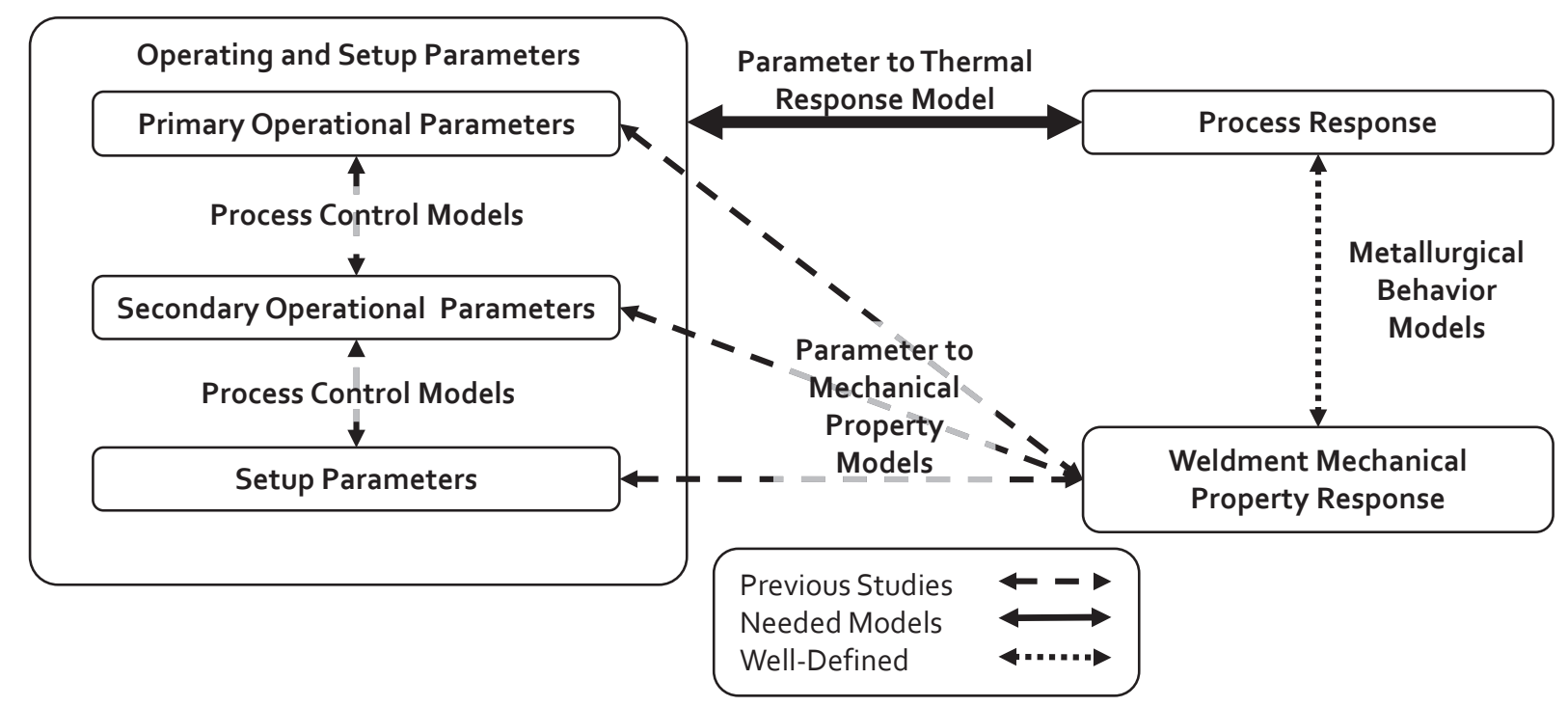

Figure 1.1: Diagram illustrating how welding parameters can be related to weld mechanical properties via a thermal response model.

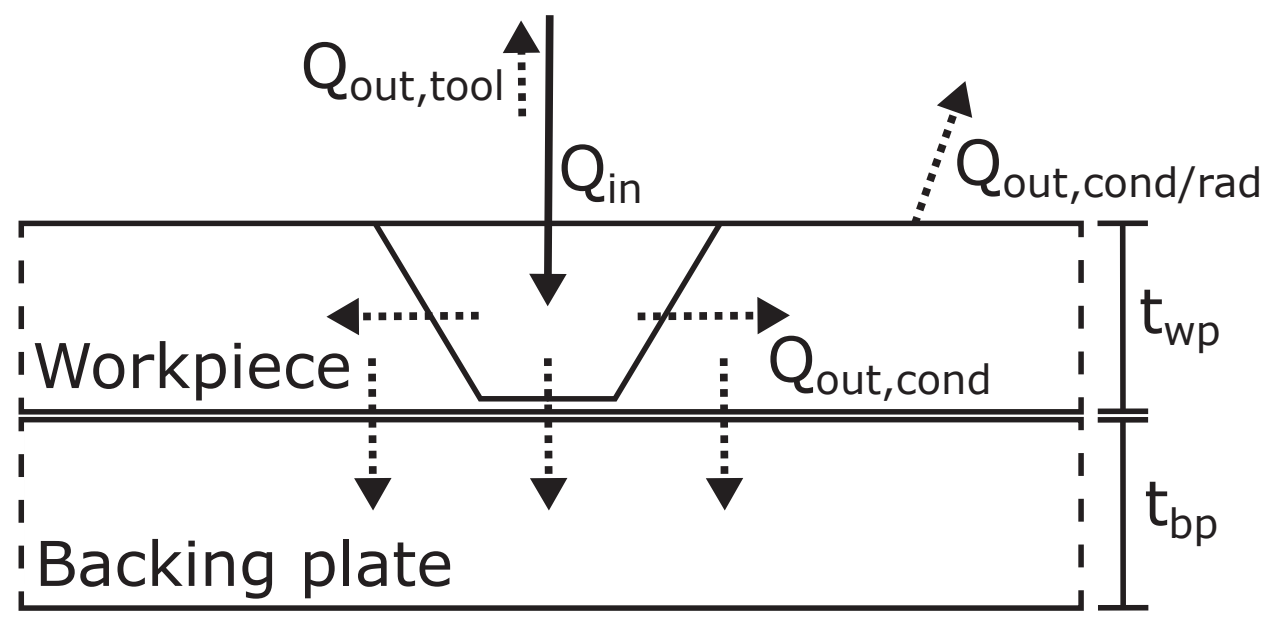

Figure 1.2: Volumetric heat flow relative to the weld nugget during friction stir welding. Assumptions: Weld has reached steady state, plate width is semi-infinite, $Q_{\text {conv } / \mathrm{rad}}<<Q_{\text {cond }}$, no heat transfer occurs between the backing plate and the anvil beneath it, $Q_{\text {out }, \text { tool }}$ is small. 


\section{CHAPTER 2. METHODS}

The approach to this study consisted of two distinct parts: 1) obtaining experimental peak temperature rise and cooling rate data from the HAZ of welds over a range of setup and operational parameters, and 2) using the data to create an empirical correlation between critical welding parameters and the thermal response of the weld.

\subsection{Experimental Data}

Experimental data from full-penetration, bead-on-plate friction stir welds was collected to create the correlation between welding setup/operational parameters and the resulting peak temperature rise and cooling rate in the weld HAZ.

Two separate experiments were performed using different workpiece materials and three different backing plates per workpiece material.

In the first experiment, Al 7075-T7351 was welded using a hardened H13 steel, convex scroll shoulder step spiral (CS4) tool with a threaded pin (see Appendix A for drawing). The backing plates used in this experiment were AL6XN, Al 6061, and copper. Type K thermocouples were embedded in the advancing side weld HAZ to record the temperature-versus-time profile at various locations. Holes were drilled from the underside of the plate to position the thermocouples at y positions of 7, 9, 11, and $13 \mathrm{~mm}$ from the weld centerline and a $\mathrm{z}$ position of $4.76 \mathrm{~mm}$ from the top surface of the plate. Thermocouples were held in place using ceramic tip holders and high thermal conductivity cement. The operating parameters used in the Al 7075 experiment ranged from travel speeds of $1.3 \mathrm{~mm} / \mathrm{s}$ to $6.3 \mathrm{~mm} / \mathrm{s}$ and weld powers from $2000 \mathrm{~W}$ to $4700 \mathrm{~W}$.

Data for the second experiment dataset was provided by Rose [30]. In his study, HSLAX65 steel was welded using a MegaStir model E44111 polycrystalline cubic boron nitride (PCBN) CS4 tool (see Appendix A for drawing). The backing plates used in this experiment were granite, AL6XN, and 1018 steel. Thermocouples were located $3.8 \mathrm{~mm}$ from the top surface of the 
workpiece at 4.6, 6.1, and $7.6 \mathrm{~mm}$ from the weld centerline in the advancing side of the tool. Thermocouples for this study were held in place by the solid thermocouple wire's compliance. The operating parameters used in the HSLA-65 experiment ranged from travel speeds of $1.2 \mathrm{~mm} / \mathrm{s}$ to $4.4 \mathrm{~mm} / \mathrm{s}$ and weld powers from $2000 \mathrm{~W}$ to $5300 \mathrm{~W}$.

The thicknesses and thermal properties of workpieces and backing plates used in the experiments are shown in Table 2.1.

Table 2.1: Thicknesses and properties of materials used in this study.

\begin{tabular}{llccc}
\hline ID & Material & $t\left(\cdot 10^{-3} m\right)$ & $\alpha\left(\cdot 10^{-6} m^{2} / s\right)$ & $k(W / m \cdot K)$ \\
\hline WP1 & A1 7075-T7351 & 9.53 & 65 & 155 \\
BP1-1 & AL6XN & 12.7 & 2.9 & 11.8 \\
BP1-2 & Al 6061 & 12.7 & 65 & 155 \\
BP1-3 & Copper (99\% pure) & 12.7 & 114 & 391 \\
\hline WP2 & X65 HSLA Steel & 6.35 & 8 & 30 \\
BP2-1 & Granite & 19.1 & 2.25 & 4 \\
BP2-2 & AL6XN & 6.35 & 2.9 & 11.8 \\
BP2-3 & 1018 Steel & 6.35 & 12.76 & 37 \\
\hline
\end{tabular}

A total of 12 welds involving 96 embedded thermocouples were performed on the Al 7075 while a total of 10 welds involving 90 embedded thermocouples were performed on the HSLA-65 steel. Of the 186 datasets obtained, 157 provided continuous and error-free information which could confidently be used to create the correlation.

The output data collected was peak temperature rise $(\theta)$ and cooling rate $(\beta)$ at each thermocouple in the HAZ. Peak temperature rise $\theta$, or the difference between the peak temperature and the initial temperature, was used instead of peak temperature as is the convention in conduction heat transfer analyses [10,31].

The cooling rate $\beta$ was determined using $\beta=\left(T_{1}-T_{2}\right) /\left(t_{2}-t_{1}\right) . T_{1}$ and $T_{2}$ were defined differently for both experiments, since the post-weld properties for HSLA-65 and Al 7075-T7351 depend on different critical temperature ranges. For Al 7075: $T_{1}=T_{p e a k}, T_{2}=150^{\circ} \mathrm{C}$. For HSLA65: $T_{1}=800^{\circ} C, T_{2}={ }^{\circ} 500$. The stated range for $\mathrm{Al} 7075$ was used because the majority of precipitation stops below $150^{\circ} \mathrm{C}$. The stated range for HSLA-65 steel was chosen because the 
phase transformation that affects its resulting microstructure and properties occurs between 800 and $500^{\circ} \mathrm{C}$ [32]. See Appendix B for example calculation from temperature versus time plot.

\subsection{Modeling Approach}

The large number of operating and setup parameters in FSW makes it difficult to identify widely applicable relationships between welding parameters and the resulting weld properties.

Dimensional analysis or non-dimensionalization is a mathematical process of simplifying a complex process by reducing the number of independent variables needed to specify the process [33]. FSW is an ideal candidate for non-dimensionalization because of the large number of welding parameters involved and the complex relationships between them. The modeling portion of the approach consisted of 1) the derivation of dimensionless variables of critical welding parameters, and 2) creation of a non-dimensional, empirical model using the collected data.

\subsubsection{Derivation of Non-Dimensional Parameters}

The non-dimensional parameters relevant to the thermal response of friction stir welding were derived using Buckingham's Pi theorem [33]. The critical parameters fundamentally related to the peak temperature rise and cooling rate at a specific location $y$ and $z$ in the weld were identified in Chapter 1 and are listed in Table 2.2.

A complete, dimensionally independent (CDI) subset of parameters were selected to nondimensionalize the dependent and other independent variables of the process. Because there are four basic units relative to the FSW process (mass, length, time, temperature), there may be up to four parameters in the CDI subset. The four selected CDI subset parameters $\left(v, Q, \alpha_{w p}\right.$, and $\left.k_{w p}\right)$ indicated in Table 2.2 met several criteria to form an acceptable subset as defined by Buckingham's Pi theorem [33]. The CDI subset was also found to be consistent with the CDI subset derived algebraically using Rosenthal's equation as shown later.

The remaining independent parameters not included in the CDI subset were non-dimensionalized to form the relevant independent $\Pi$ numbers given by Equations 2.1-2.6. The outputs of interest,

$\theta$ and $\beta$ were also non-dimensionalized as shown in Equations 2.7 and 2.8 for use in the nondimensional correlation described in Section 2.2.2. 
Table 2.2: Critical parameters and their units used in non-dimensional modeling of FSW.

\begin{tabular}{lccc}
\hline Parameter Category & Parameter & Units* & $\Pi \#$ \\
\hline CDI Subset & $k_{w p}$ & $M^{1} L^{1} t^{-3} T^{-1}$ & N/A \\
CDI Subset & $\alpha_{w p}$ & $L^{2} t^{-1}$ & N/A \\
CDI Subset & $v$ & $L^{1} t^{-1}$ & N/A \\
CDI Subset & $Q$ & $M^{1} L^{2} t^{-3}$ & N/A \\
Independent $\Pi \#$ & $y$ & $L^{1}$ & Eq. 2.1 \\
Independent $\Pi \#$ & $z$ & $L^{1}$ & Eq. 2.2 \\
Independent $\Pi \#$ & $t_{w p}$ & $L^{1}$ & Eq. 2.3 \\
Independent $\Pi \#$ & $t_{b p}$ & $L^{1}$ & Eq. 2.4 \\
Independent $\Pi \#$ & $\alpha_{b p}$ & $L^{2} t^{-1}$ & Eq. 2.5 \\
Independent $\Pi \#$ & $k_{b p}$ & $M^{1} L^{1} t^{-3} T^{-1}$ & Eq. 2.6 \\
Dependent $\Pi \#$ & $\theta$ & $T^{1}$ & Eq. 2.7 \\
Dependent $\Pi \#$ & $\beta$ & $T^{1} t^{-1}$ & Eq. 2.8 \\
\hline
\end{tabular}

*Units: $M=$ Mass, $L=$ Length, $t=$ Time, $T=$ Temperature

$$
\begin{gathered}
\Pi_{y}=\frac{y \cdot v}{2 \cdot \alpha_{w p}} \\
\Pi_{z}=\frac{z \cdot v}{2 \cdot \alpha_{w p}} \\
\Pi_{t_{w p}}=\frac{t_{w p} \cdot v}{2 \cdot \alpha_{w p}} \\
\Pi_{t_{b p}}=\frac{t_{b p} \cdot v}{2 \cdot \alpha_{w p}} \\
\Pi_{\alpha_{b p}}=\frac{\alpha_{b p}}{\alpha_{w p}} \\
\Pi_{k_{b p}}=\frac{k_{b p}}{k_{w p}} \\
\Pi_{\theta}=\frac{4 \cdot \pi \cdot \theta \cdot k_{w p} \cdot \alpha_{w p}}{Q \cdot v} \\
\Pi_{\beta}=\frac{8 \cdot \pi \cdot \beta \cdot k_{w p} \cdot \alpha_{w p}^{2}}{Q \cdot v^{3}}
\end{gathered}
$$

During the process of non-dimensionalization, it was discovered that substitution of $\Pi_{x}$ $\left(x \cdot v /\left(2 \cdot \alpha_{w p}\right)\right), \Pi_{y}$, and $\Pi_{z}$ into Rosenthal's equation provided a concise, non-dimensional form 
of Rosenthal's equation (Eq. 1.1). The dimensionless form of Rosenthal's equation is given by Equation 2.9 when used along with $\Pi_{\theta}$ as defined in Equation 2.7.

$$
\Pi_{\theta}=\left(\frac{1}{\Pi_{R}}\right) \exp \left[\left(\Pi_{R}+\Pi_{x}\right)\right]
$$

where $\Pi_{R}=\sqrt{\Pi_{x}^{2}+\Pi_{y}^{2}+\Pi_{z}^{2}}$.

The non-dimensional numbers derived using Buckingham's Pi theorem and those derived using Rosenthal's equation are consistent. The constants included in Equations 2.1-2.8 are included simply to provide consistency with Rosenthal's equations and do not affect the form of the model discussed in Section 2.2.2.

\subsubsection{Creation of Non-Dimensional Empirical Model}

An empirical model between the experimental data and the derived non-dimensional parameters was created for the range of operating and setup parameters mentioned in Section 2.1.

A multivariate power equation was the functional form of the fit used to create the correlation for dimensionless peak temperature rise (Equation 2.10) and dimensionless cooling rate (2.11):

$$
\Pi_{\theta}=a_{1} \cdot \Pi_{y}^{a_{2}} \cdot \Pi_{z}^{a_{3}} \cdot \Pi_{t_{w p}}^{a_{4}} \cdot \Pi_{t_{b p}}^{a_{5}} \cdot \Pi_{\alpha_{b p}}^{a_{6}}
$$

where $a_{1}=5.583 E-2, a_{2}=-3.989 E-1, a_{3}=-2.735, a_{4}=1.676, a_{5}=4.878 E-2$, and $a_{6}=-1.051 E-1$, and

$$
\Pi_{\beta}=b_{1} \cdot \Pi_{y}^{b_{2}} \cdot \Pi_{z}^{b_{3}} \cdot \Pi_{t_{w p}}^{b_{4}} \cdot \Pi_{t_{b p}}^{b_{5}} \cdot \Pi_{\alpha_{b p}}^{b_{6}}
$$

where $b_{1}=3.577 E-4, b_{2}=-4.287 E-1, b_{3}=-6.958, b_{4}=5.334=, b_{5}=-4.601 E-1$, and $b_{6}=7.795 E-2$.

The constants for these equations were determined using a linear solve of logarithmic transformations of Equations 2.12 and 2.13 which minimized the residual sum of squares:

$$
\log _{10} \Pi_{\theta}=A_{1}+a_{2} \cdot \log _{10} \Pi_{y}+a_{3} \cdot \log _{10} \Pi_{z}+a_{4} \cdot \log _{10} \Pi_{t_{w p}}+a_{5} \cdot \log _{10} \Pi_{t_{b p}}+a_{6} \cdot \log _{10} \Pi_{\alpha_{b p}}
$$




$$
\log _{10} \Pi_{\beta}=B_{1}+b_{2} \cdot \log _{10} \Pi_{y}+b_{3} \cdot \log 10 \Pi_{z}+b_{4} \cdot \log _{10} \Pi_{t_{w p}}+b_{5} \cdot \log _{10} \Pi_{t_{b p}}+b_{6} \cdot \log _{10} \Pi_{\alpha_{b p}}
$$

where $a_{1}=10^{A_{1}}$ and $b_{1}=10^{B_{1}}$

Stepwise regression was used to systematically add and identify which $\Pi$ numbers should be included in the model. All independent $\Pi$ numbers derived using Buckingham's Pi theorem were included in the final form of the model except $\Pi_{k_{b p}}$. While including $\Pi_{k_{b p}}$ improved the model adjusted $R^{2}$ by 0.02 and 0.03 percent for the $\Pi_{\theta}$ and $\Pi_{\beta}$ models, respectively, this was not considered a significant enough improvement to justify the added model complexity.

From the correlations (Equations 2.10 and 2.11), the actual $\theta$ and $\beta$ were back solved for using Equations 2.7 and 2.8. 


\section{CHAPTER 3. RESULTS AND DISCUSSION}

\subsection{Non-Dimensional Empirical Model}

Figures 3.1a and 3.1b show the correlations between the fit and measured values for dimensionless peak temperature rise and cooling rate, respectively.

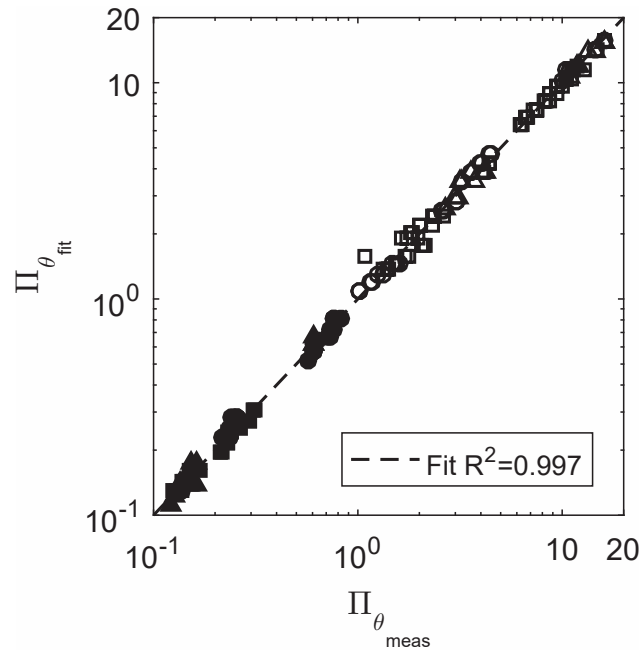

(a) $\log$ Peak temperature rise

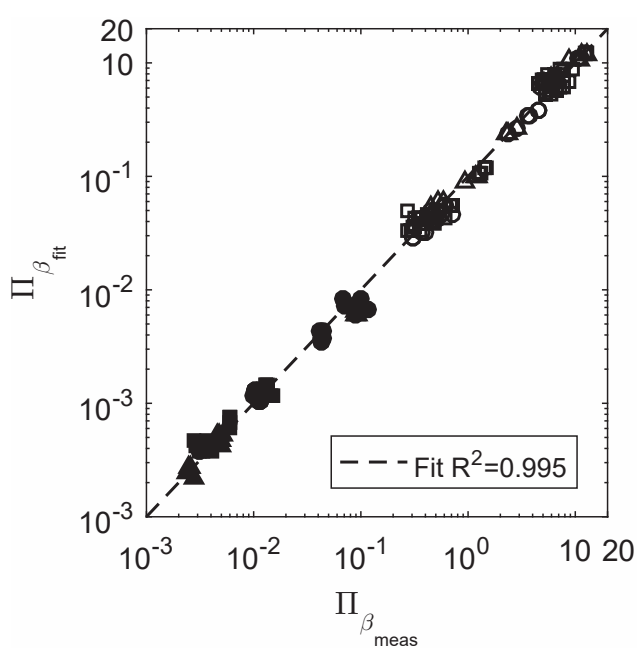

(b) $\log$ Cooling rate

Figure 3.1: Log-scale correlations between fit versus measured dimensionless peak temperature rise (a) and dimensionless cooling rate (b).

The correlations have $R^{2}$ values of 0.997 for the dimensionless peak temperature rise model and 0.995 for the dimensionless cooling rate model (Figure 3.1).

The dimensionless fits account for greater than 99 percent of the variability in the dimensionless peak temperature rise and cooling rate experimental data, despite the data spanning steel and aluminum workpiece materials, two different tools, five backing plate materials, travel speeds from 0.83 to $6.3 \mathrm{~mm} / \mathrm{s}$, and weld powers from 2000 to $5300 \mathrm{~W}$. 
Figures $3.2 \mathrm{a}$ and $3.2 \mathrm{~b}$ show the correlations between the fit and measured values for the actual peak temperature rise and cooling rate. The statistically significant $R^{2}$ does not apply to these correlations but the correlation of determination $r^{2}$ of the $\log$ transform of the correlation is 0.986 and 0.915 for peak temperature rise and cooling rate, respectively.

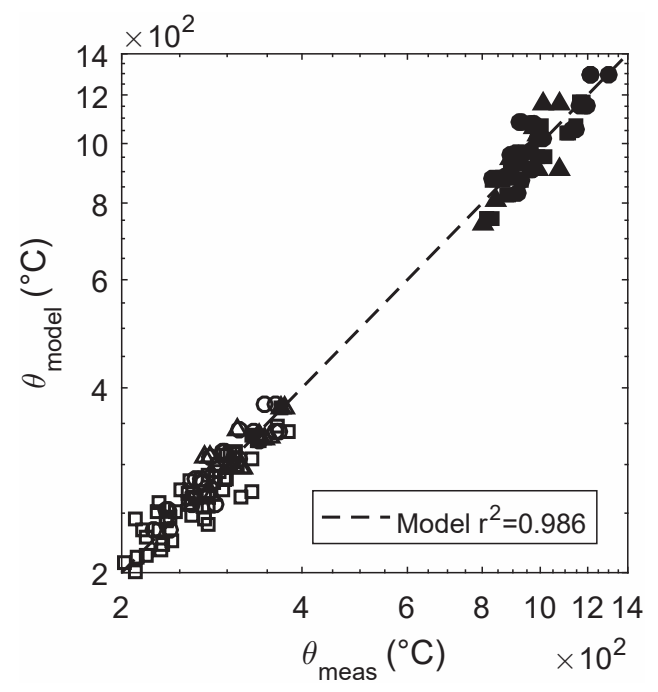

(a) $\log$ Peak temperature rise

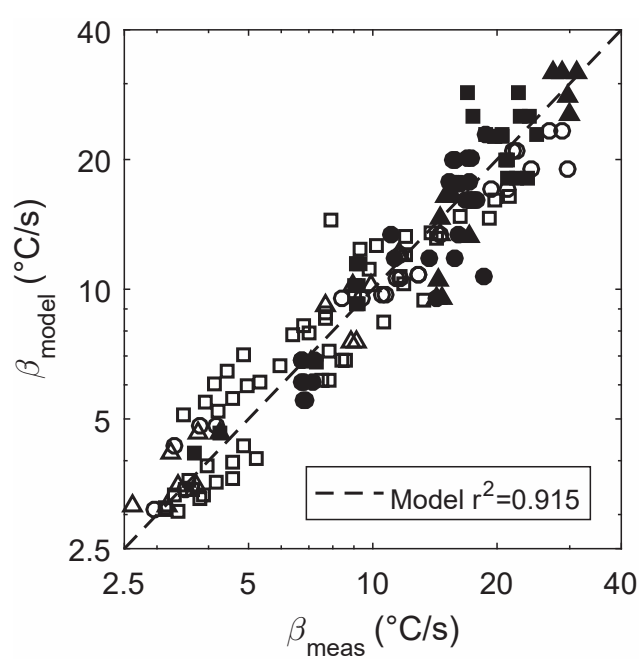

(b) $\log$ Cooling rate

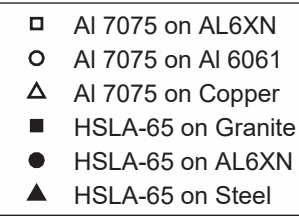

$\triangle$ Al 7075 on Copper

- HSLA-65 on Granite

- HSLA-65 on AL6XN

- HSLA-65 on Steel

Figure 3.2: Log-scale correlation between fit and measured peak temperature rise (a) and cooling rate (b).

The clustering of data in Figure 3.2a near the extremes of the axes is due to the large difference between the welding temperatures of the aluminum and steel materials used in the experiments. Inclusion of other materials with a FSW temperature between $500-1000{ }^{\circ} C$ such as copper or titanium-6Al-4V would make this data more uniformly distributed along the correlation.

Several factors could contribute to the error between the fit and measured values shown in Figures 3.2a and 3.2b. The first potential cause is uncertainty in the actual thermal properties used in the calculations due to the use of room temperature tabular thermal properties in the calculations. It is expected that the model's accuracy would improve by using experimentally determined, temperature-dependent property values instead of assumed tabular values.

Additionally, tool shift during welding and uncertainty in the thermocouple location relative to the tool position could have introduced error. The steep thermal gradient in the HAZ increases the uncertainty introduced by both of these sources of error. 
Finally, a lack of contact between the thermocouples and the bottom of the thermocouple positioning holes could have introduced error. Every effort was made to ensure intimate contact between the thermocouples and the bottom of the location holes. However, thermocouple movement may still have occurred to introduce error in the fit.

\subsection{Application of Model}

\subsubsection{Estimation of Weld Power}

Attempts were made to apply the model to existing studies to test its accuracy in practical applications. However, few studies report the parameters necessary to use the model.

Simar et al. investigated the role of backing plate and heat source type in FSW finite element thermal modeling [34]. This study reported critical welding parameters and peak temperature data from embedded thermocouples and enabled application of the model. The experiment used an alloy (Al 6005) not used for the development of the model in addition to a much higher range of travel speeds (3.3-16.7 mm/s) and a higher range of weld powers $(3000-6000 \mathrm{~W})$. The actual experimental weld power was compared with the model-predicted weld power which would produce the reported peak temperature rise for each thermocouple location and set of welding parameters. Comparisons using the cooling rate model were not performed since cooling rate data was not reported.

The setup and operating parameters provided by Simar et al. was first used to calculate $\Pi_{\theta_{\text {predicted }}}$ using Equation 2.10 for their five travel speed and weld power data sets. Only data from thermocouples in the advancing side of the tool were used to maintain consistency with the model.

The predicted power from each experiment and thermocouple was then calculated using Equation 2.7 as shown:

$$
Q_{\text {pred }}=\frac{4 \cdot \pi \cdot \theta_{\text {actual }} \cdot k_{w p} \cdot \alpha_{w p}}{\Pi_{\theta_{\text {predicted }}} \cdot v}
$$

Figure 3.3 shows the ratio of predicted to actual weld power versus distance from the workpiece top-centerline for each thermocouple location. Vertical spread in the data is due to the different travel speeds and weld powers used. The figure distinguishes between the power ratios calculated from thermocouples at workpiece mid-thickness $\left(\mathrm{z} / \mathrm{t}_{\mathrm{wp}}=0.5\right)$ and those deeper in the 


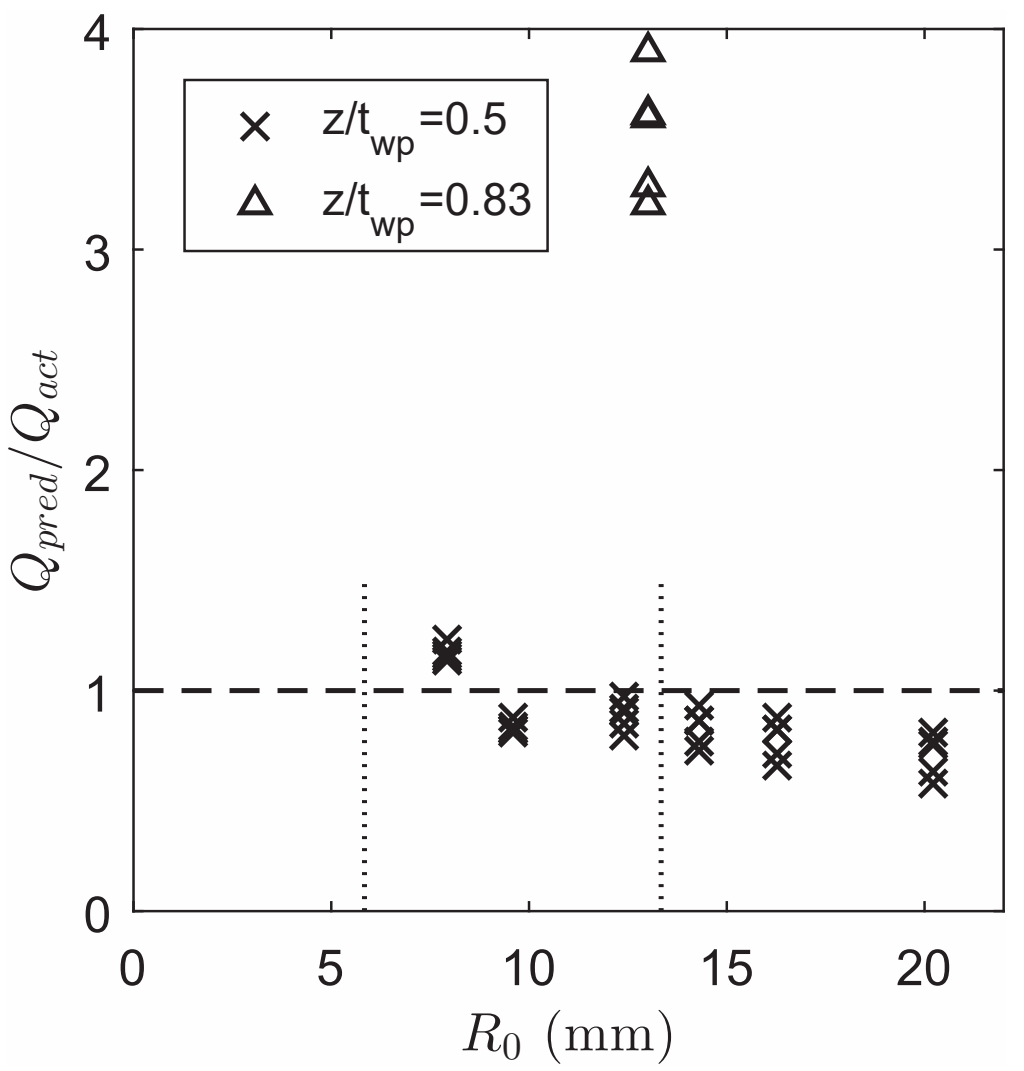

Figure 3.3: Ratio of predicted to actual power versus thermocouple distance $R_{0}$ from weld center at the top of the workpiece where $R_{0}=\sqrt{y^{2}+z^{2}}$ for each thermocouple location.

workpiece near the backing plate $\left(\mathrm{z} / \mathrm{t}_{\mathrm{wp}}=0.83\right)$. When considering only the data from thermocouples at workpiece mid-thickness (denoted by X markers in Figure 3.3), the model predicted an average of 87 percent of the actual weld power (with a standard deviation of 16 percent).

The model improves to predict an average of 96 percent of the weld power when considering only the thermocouples within the normalized distance used to create the model (indicated between the vertical dotted lines of Figure 3.3). Thermocouples in Simar's study were placed at a greater distance from the welding centerline than those used to create the model.

Also, the outlying data denoted by the triangle markers in Figure 3.3 shows that the model does not accurately account for variation in z-position. These outlying markers denote the data from a thermocouple location at a z-position of 83 percent of the workpiece thickness. However, all the thermocouples used to create the correlation were located between 50 and 60 percent of the workpiece thickness. 
The model accurately predicts the weld power for thermocouples within the range of positions used when creating the correlation despite being applied to a workpiece material not used to create the model. Further studies which include thermocouples at a great y-distance from the weld source and statistically varied z-distance would improve the model's accuracy.

\subsubsection{Parameter Control for Desired Cooling Rate}

In welding of steels, it is often important to control the cooling rate from 800 to 500 degrees $\mathrm{C}$ in order to avoid adverse phases like martensite [32]. The desired cooling rate is often achieved by preheating the workpiece or controlling heat input. In friction stir welds, these adverse phases have been shown to reduce weld fracture toughness [35-37]. Nelson et al. showed that the adverse microstructure could be eliminated when the cooling rate in the weld HAZ was less than 20 degrees C per second $[21,30]$.

The model was used to explore welding parameters required to produce a cooling rate below 20 degrees C per second for Nelson's experimental setup. Figure 3.4 shows cooling rate contours as a function of travel speed and backing plate thermal diffusivity for a weld power of $4500 \mathrm{~W}$ in HSLA-65. Any combination of travel speed and backing plate in the shaded region could be used to achieve a cooling rate below the critical 20 degrees $\mathrm{C}$ per second.

This figure shows just one example of how the model may be applied to identify needed welding parameters. Critical cooling rate information could be obtained for any material of interest using CCT diagram. The model could then be used to identify combinations of any welding parameters needed to achieve that cooling rate.

Figure 3.4 also compares Nelson's experimental cooling rates to those predicted by the model. The model predicted an average of 17.5 percent higher cooling rate for the experimental data shown. Possible sources of experimental error include: 1) thermocouple placement and drilling, 2) misalignment between the weld centerline and tool during setup, and 3) tool shift from the forces of loading during welding.

Additional error could have been introduced based on the experiment design. For both

the steel and aluminum experiments used to create the model, a constant backing plate thickness for each backing plate thermal diffusivity was used. This lack of statistical variation in backing plate thickness could adversely affect the fit of the model. This discrepancy is an artifact of using 


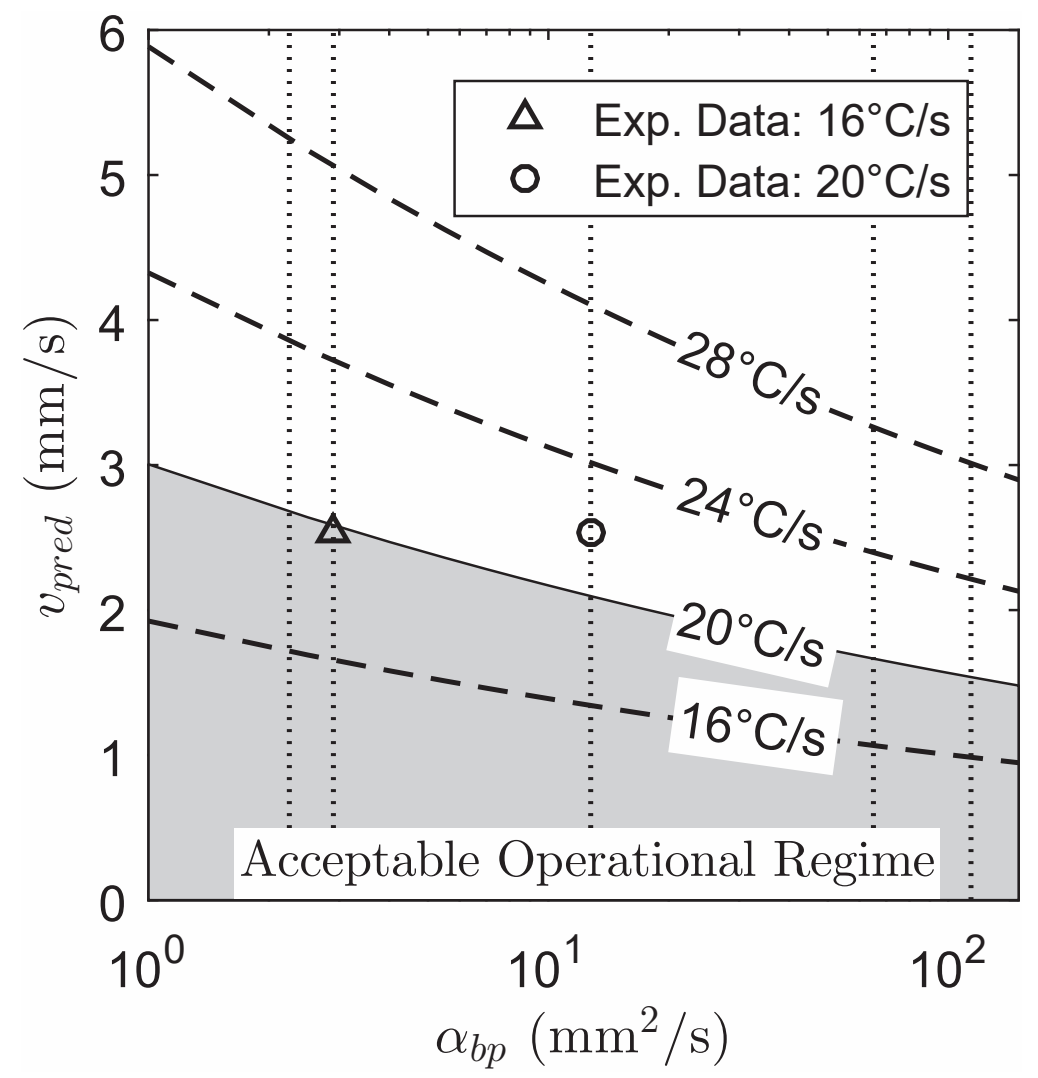

Figure 3.4: Predicted travel speed versus backing plate thermal diffusivity for a given cooling rate created according to the model. Vertical dotted lines represent thermal diffusivities of various backing plates (from left to right): Granite, AL6XN, 1018 Steel, Al6061, 99 \% Pure Copper.

others' data not designed specifically for creating this model. Further studies are likely needed to statistically vary and more fully investigate the effect of backing plate thickness.

\subsubsection{Relative Importance of Weld Parameters}

As evident from the literature, there is a lack of understanding of the relative effects of welding parameters on resulting weld properties. For example, Nelson found that $v$ and $\alpha_{b p}$ had a similar relative importance in how these parameters affected the resulting weld properties in HSLA-65 steel [21]. Dickson found that $v$ had a much greater relative importance than $\alpha_{b p}$ on the weld properties in Al 7075 [20]. Others have also reported varying conclusions regarding the role of specific parameters [13, 19, 22]. 
The reported difference in the relative importance of welding parameters is likely due to two primary considerations: 1) the non-linear relationship between welding parameters and resulting properties, and 2) the different parameter ranges used between studies.

The model was first used to illustrate how $\theta$ and $\beta$ vary non-linearly with welding parameters. Figure 3.5 shows peak temperature and cooling rate as a function of travel speed and backing plate thermal diffusivity according to the model. The purpose of the different parameter ranges, vertical lines, and $\Delta_{\theta}$ and $\Delta_{\beta}$ values will be discussed shortly. The relationships between outputs $\left(\theta\right.$ and $\beta$ ) and the parameters $\left(v\right.$ and $\left.\alpha_{b p}\right)$ are highly non-linear in most cases. Specifically, the peak temperature of the weld is more sensitive to changes in travel speed and backing plate thermal diffusivity at lower values of these parameters than at higher values (Figure 3.5a and 3.5b). The cooling rate is approximately linearly dependent on travel speed over a range of viable travel speeds (Figure 3.5c) but is much more sensitive to changes in backing plate thermal diffusivity at low values (Figure 3.5d).

The model was next used to illustrate how the relative importance of parameters depends on the range used. The relative importance of $\alpha_{b p}$ and $v$ on $\theta$ and $\beta$ was compared for two different parameter ranges indicated in Figure 3.5. The relative importance of $\alpha_{b p}$ to $v$ is defined mathematically as $\Delta_{f\left(\alpha_{b p}\right)} / \Delta_{f(v)}$, where $\Delta_{f\left(\alpha_{b p}\right)}$ is the percent change in the resulting properties over the range of $\alpha_{b p}$ 's used in the study, and $\Delta_{f(v)}$ is the percent change in the resulting properties over the range of $v$ 's used in the study. These $\Delta_{f}$ values for the two parameter ranges compared are indicated in the plot and figure caption. The $\Delta_{f}$ for each parameter was calculated over an average of the other parameters to avoid introducing variation due to the other parameter.

Figure 3.6 shows a summary of the relative importance of backing plate thermal diffusivity versus travel speed for the two parameter ranges. The lines of constant slope indicate a constant relative importance. The unshaded region indicates when $\alpha_{b p}$ is of greater relative importance while the shaded region indicates when $v$ is of greater relative importance.

The parameter of greatest importance changes from $v$ for parameter range 1 (unfilled circle and diamond markers) to $\alpha_{b p}$ for parameter range 2 (unfilled circle and diamond markers) by simply shifting the $v$ range expanding the $\alpha_{b p}$ range. The data in Figure 3.6 indicates the most relevant parameter for a particular study is dependent upon the range of parameters investigated. 


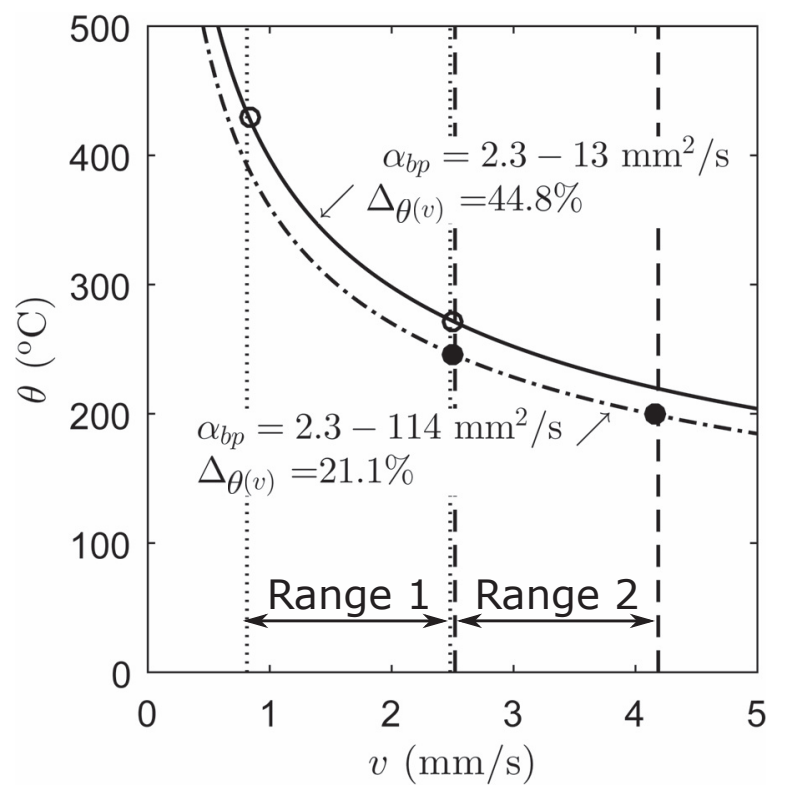

(a)

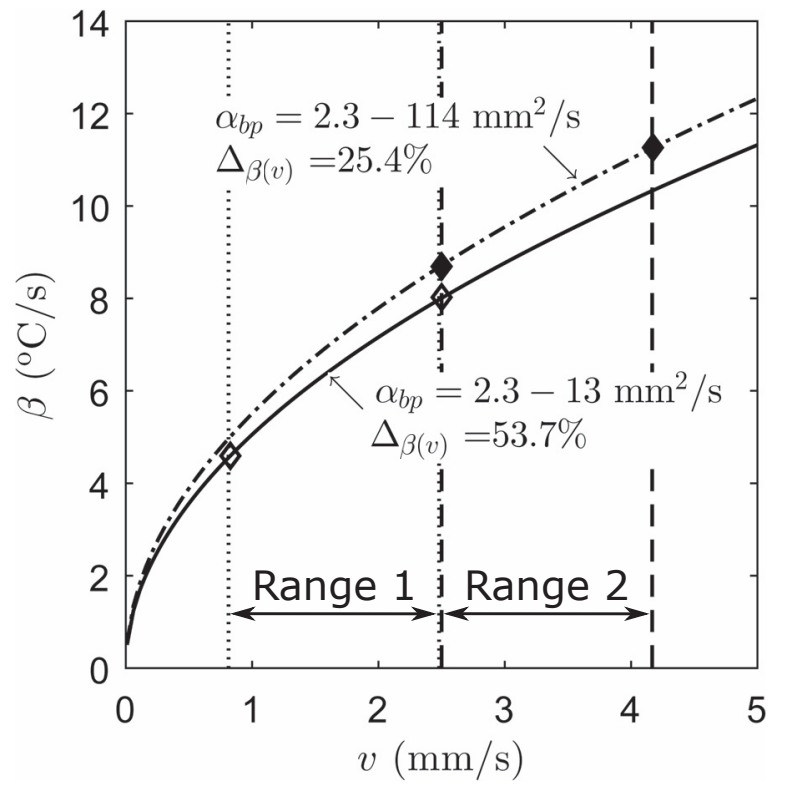

(c)

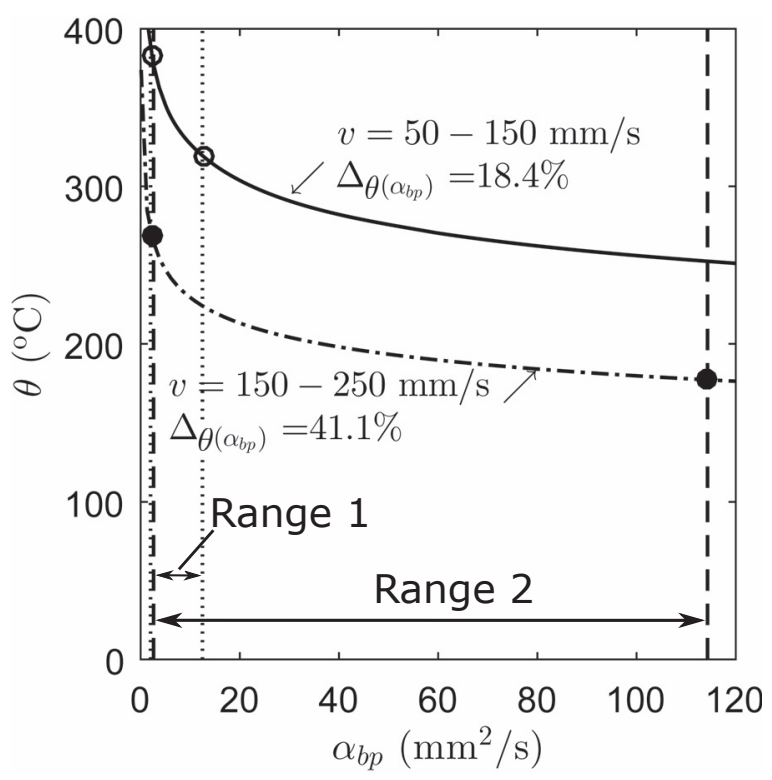

(b)

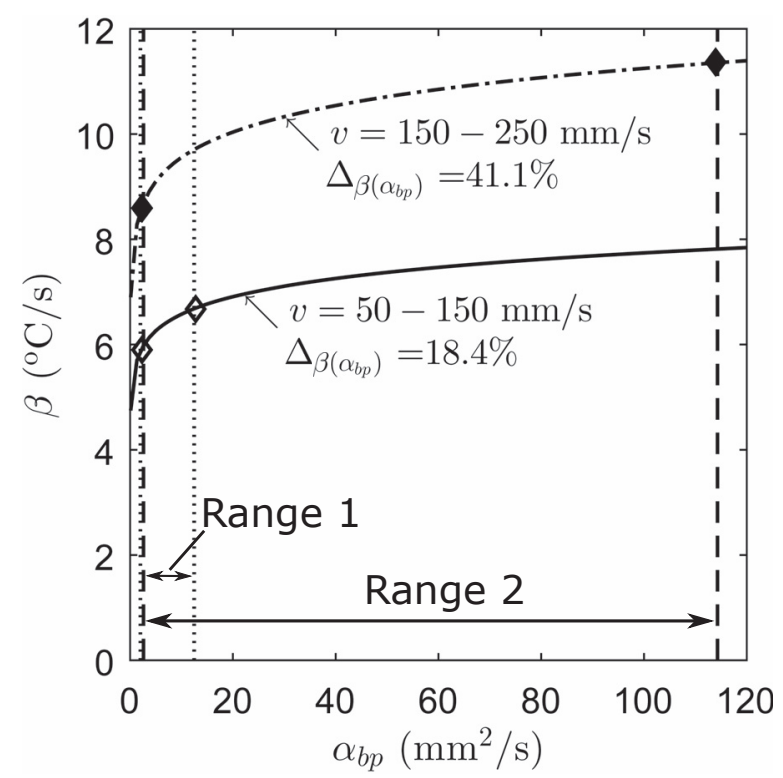

(d)

Figure 3.5: Effects of different $v$ and $\alpha_{b p}$ parameter ranges on $\theta$ and $\beta$ according to model. Parameter range 1 (denoted by a curves made of a solid line with unfilled markers) corresponds to a range of $v=0.83-2.5 \mathrm{~mm} / \mathrm{s}$ and $\alpha_{b p}=2.3-13 \mathrm{~mm}^{2} / \mathrm{s}$. Parameter range 2 (denoted by curves made of a dash-dot line with filled markers) corresponds to a range of $v=2.5-4.17 \mathrm{~mm} / \mathrm{s}$ and $\alpha_{b p}=2.3-114 \mathrm{~mm}^{2} / \mathrm{s}$.

Other parameters held constant constant (WP material: Al 7075; WP thickness: $9.53 \mathrm{~mm}$; BP thickness: $6.35 \mathrm{~mm}$; weld power: $2400 \mathrm{~W}$ ) Vertical dotted lines correspond to parameter range 1; vertical dashed lines correspond to parameter range 2 . 
To fully capture the process, one must study a wide enough parameter range to capture the nonlinearity.

Dickson's experimental hardness data over the same parameter range as in range 1 is also plotted on Figure 3.6 for validation of the model. Both sets of unfilled markers lie near the relative importance line of $1 / 3$ which indicates $v$ and $\alpha_{b p}$ have a similar relative importance for the HAZ and nugget hardness as for $\theta$ and $\beta$. It is expected that the parameter of greatest relative importance to the hardness properties would change from $v$ to $\alpha_{b p}$ if the experimental parameter range were changed from parameter range 1 to 2 . 


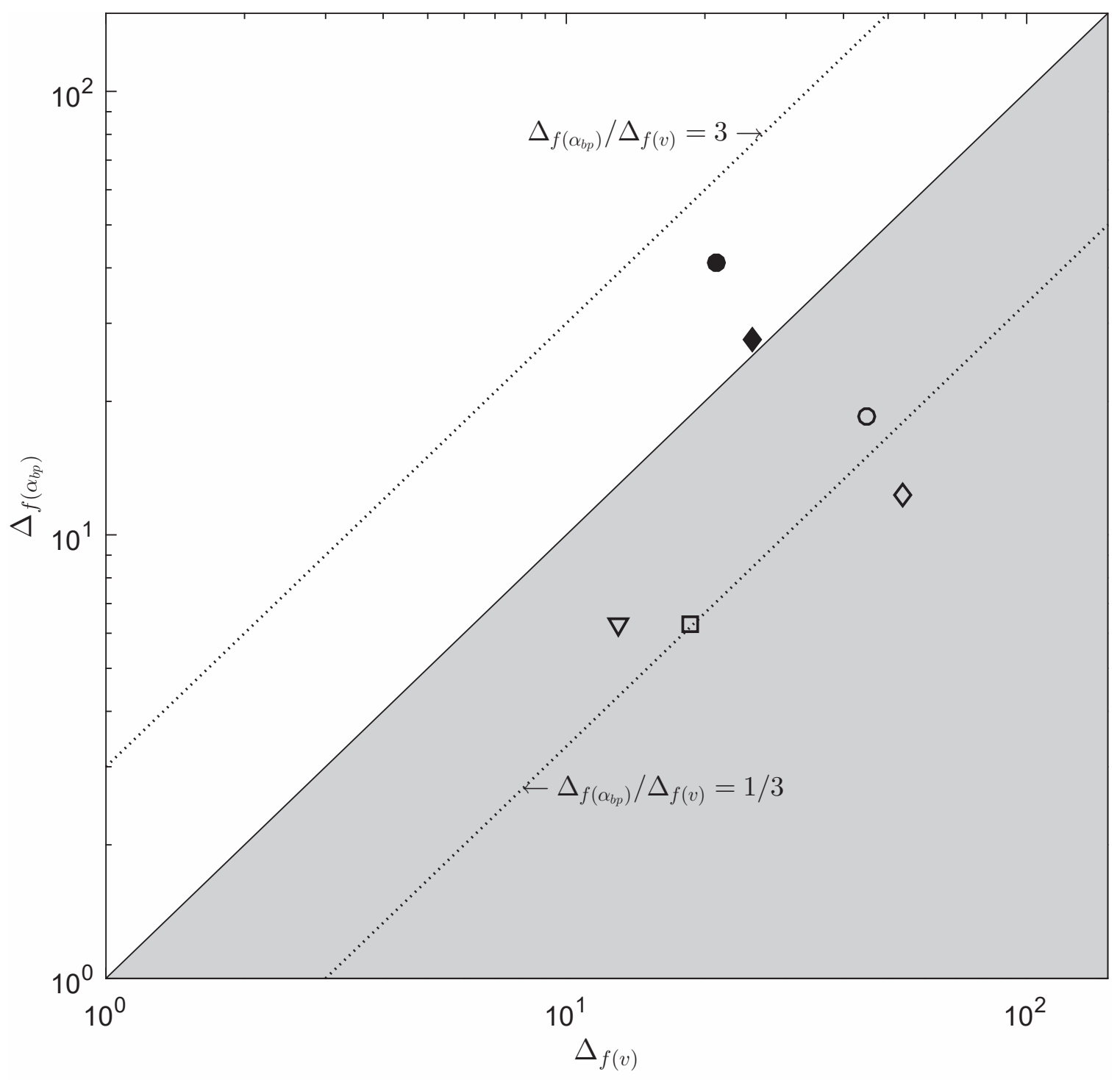

O Model: $\theta$ (Range 1: $v=50-150 \mathrm{~mm} / \mathrm{s}, \alpha_{b p}=2.3-13 \mathrm{~mm}^{2} / \mathrm{s}$ )

$\diamond$ Model: $\beta$ (Range 1: $v=50-150 \mathrm{~mm} / \mathrm{s}, \alpha_{b p}=2.3-13 \mathrm{~mm}^{2} / \mathrm{s}$ )

- Model: $\theta$ (Range 2: $v=150-250 \mathrm{~mm} / \mathrm{s}, \alpha_{b p}=2.3-114 \mathrm{~mm}^{2} / \mathrm{s}$ )

$\checkmark$ Model: $\beta$ (Range 2: $v=150-250 \mathrm{~mm} / \mathrm{s}, \alpha_{b p}=2.3-114 \mathrm{~mm}^{2} / \mathrm{s}$ )

$\square$ Dickson Experiment: Nugget HV (Range 1: $\mathrm{v}=50-150 \mathrm{~mm} / \mathrm{s}, \alpha_{b p}=2.3-13 \mathrm{~mm}^{2} / \mathrm{s}$ )

$\nabla$ Dickson Experiment: HAZ HV (Range 1: $\mathrm{v}=50-150 \mathrm{~mm} / \mathrm{s}, \alpha_{b p}=2.3-13 \mathrm{~mm}^{2} / \mathrm{s}$ )

Figure 3.6: Relative importance of $\alpha_{b p}$ and $v$ for two different ranges of weld peak temperature rise and cooling rate (model) and weld properties (experimental). $\Delta_{f\left(\alpha_{b p}\right)} / \Delta_{f(v)}>1$ indicates that $\alpha_{b p}$ is of greater relative importance in determining the resulting properties whereas $\Delta_{f\left(\alpha_{b p}\right)} / \Delta_{f(v)}<1$ indicates that $v$ is of greater relative importance. 


\section{CHAPTER 4. CONCLUSIONS}

The welding operational and setup parameters which are sufficient to predict the peak temperature rise and cooling rate of the weld include travel speed, weld power, workpiece thermal conductivity, workpiece thermal diffusivity, workpiece thickness, backing plate thermal diffusivity, and backing plate thickness. These parameters are shown to fundamentally affect the heat transfer of the process.

Of these parameters, weld power and backing plate information are the least reported in the literature despite being fundamentally related to the heat transfer and resulting properties in FSW. We recommend reporting weld power and backing plate geometry and thermal properties for all FSW experiments to allow effective comparison of results between studies.

A physics-based, empirical model has been created which correlates operational and setup parameters to the peak temperature and cooling rate at any location of the heat-affected zone of friction stir welds. The model has an R-squared of greater than 0.99 for both the dimensionless peak temperature rise and cooling rate correlations. It was created using 22 individual welds and 157 data points over two different tools, two different workpiece materials (steel and aluminum), and five different backing plate materials (from high thermal diffusivity copper to low thermal diffusivity granite) as well as travel speeds from about 0.83 to $6.3 \mathrm{~mm} / \mathrm{s}$ and weld powers from 2000 to $5300 \mathrm{~W}$.

The model can be used to estimate the power required to produce a desired peak temperature rise. When tested against Simar's well-reported data for a different alloy not used to create the correlation, the model predicts an average power of 87 percent of the actual weld power.

The model can also be used to identify the maximum travel speed for a given backing plate which may be used while remaining below a known critical cooling rate to avoid the formation of an adverse microstructure in HSLA steels. When compared with actual data from an experiment 
using HSLA-65 steel, the model predicted an average of 17.5 percent higher cooling rate than the data considered.

The peak temperature of the weld is more sensitive to changes in travel speed and backing plate thermal diffusivity at lower values of these parameters than at higher values per the model. Also, the cooling rate is approximately linearly dependent on travel speed but is much more sensitive to changes in backing plate thermal diffusivity at low values.

By changing the ranges of the parameters under study, one can change the relative importance of backing plate thermal diffusivity and travel speed on the peak temperature rise and cooling rate of the weld. For the parameter ranges used in the two hypothetical studies using the model, the relative importance of backing plate thermal diffusivity to travel speed changes from 0.42 to 1.97 for peak temperature and from 0.24 to 1.14 for cooling rate. Therefore, any general claim that one parameter is more important than another in determining resulting properties is a flawed argument. The model illustrates how the selection of the range of welding parameters can largely determine the relative importance of one parameter versus another.

The model predicts a similar relative importance of backing plate to travel speed for peak temperature rise and cooling rate as for experimentally determined nugget and HAZ hardness in Al 7075 over the same range of operating and setup parameters. This is shown in Figure 3.6 by both sets of unfilled points lying on the same sloped line on the log-log plot. 


\section{CHAPTER 5. FUTURE WORK}

This work has identified further studies which would improve the accuracy and applicability of the peak temperature rise and cooling rate models.

Experiments involving greater statistical variation of the following parameters would further improve the models:

- workpiece thickness $\left(t_{w p}\right)$

- backing plate thickness $\left(t_{b p}\right)$

- thermocouple depth $(z)$

- thermocouple distance from the weld center line $(y)$

Experiments involving a workpiece such as copper with an intermediate welding temperature between the aluminum and steel used in this study would provide a more evenly distributed peak temperature rise correlation (Figure 3.2a). Also, experiments exploring the effect of dimensionless plate width $\left(\right.$ width $\left.\cdot v /\left(2 \cdot \alpha_{w p}\right)\right)$ on the dimensionless peak temperature rise and cooling rate could prove useful in cases where narrow plate widths are used.

Other relevant future work includes uncertainty analysis of thermocouple placement, plate alignment, and tool shift to quantify the model error.

Finally, exploration of dimensionless model functional forms different from the power fit used herein may provide a more physically accurate model fit. 


\section{REFERENCES}

[1] W. Thomas, E. Nicholas, J. Needham, M. Murch, P. Templesmith, and C. Dawes, "Friction-stir butt welding, gb patent no. 9125978.8, international patent application no," PCT/GB92/02203, Tech. Rep., 1991. 1

[2] Y. S. Sato, M. Urata, and H. Kokawa, "Parameters controlling microstructure and hardness during friction-stir welding of precipitation-hardenable aluminum alloy 6063," Metallurgical and Materials Transactions A, vol. 33, no. 3, pp. 625-635, 2002. 1

[3] M. Peel, A. Steuwer, M. Preuss, and P. J. Withers, "Microstructure, mechanical properties and residual stresses as a function of welding speed in aluminium AA5083 friction stir welds," Acta Materialia, vol. 51, no. 16, pp. 4791-4801, 2003. 1, 3

[4] H. J. Liu, H. Fujii, M. Maeda, and K. Nogi, "Tensile properties and fracture locations of friction-stir-welded joints of 2017-T351 aluminum alloy," Journal of Materials Processing Technology, vol. 142, no. 3, pp. 692-696, 2003. 1

[5] K. a. a. Hassan, P. B. Prangnell, a. F. Norman, D. a. Price, and S. W. Williams, "Effect of welding parameters on nugget zone microstructure and properties in high strength aluminium alloy friction stir welds," Science and Technology of Welding and Joining, vol. 8, no. 4, pp. 257-268, 2003. 1, 3

[6] A. P. Reynolds, W. Tang, Z. Khandkar, J. a. Khan, and K. Lindner, "Relationships between weld parameters, hardness distribution and temperature history in alloy 7050 friction stir welds," Science and Technology of Welding and Joining, vol. 10, no. 2, pp. 190-199, 2005. 1

[7] J. H. Record, "Statistical Investigation of Friction Stir Processing Parameter Relationships," MS, Brigham Young University, 2005. 1

[8] J. W. Pew, “A Torque-Based Weld Power Model for Friction Stir Welding,” Ph.D. dissertation, Brigham Young University, 2006. 1

[9] P. Cavaliere, A. Squillace, and F. Panella, "Effect of welding parameters on mechanical and microstructural properties of AA6082 joints produced by friction stir welding," Journal of Materials Processing Technology, vol. 200, no. 1-3, pp. 364-372, 2008. 1

[10] A. Arora, G. G. Roy, and T. Debroy, "Cooling rate in 800 to $500 \mathrm{C}$ range from dimensional analysis," Science and Technology of Welding and Joining, vol. 15, no. 5, pp. 423-428, 2010. $1,3,7$

[11] A. Arora, T. Debroy, and H. K. D. H. Bhadeshia, "Back-of-the-envelope calculations in friction stir welding Velocities , peak temperature , torque , and hardness," 
Acta Materialia, vol. 59, no. 5, pp. 2020-2028, 2011. [Online]. Available: http: //dx.doi.org/10.1016/j.actamat.2010.12.001 1, 3

[12] S. Rajakumar, C. Muralidharan, and V. Balasubramanian, "Predicting tensile strength, hardness and corrosion rate of friction stir welded AA6061-T6 aluminium alloy joints," Materials and Design, vol. 32, no. 5, pp. 2878-2890, 2011. [Online]. Available: http://dx.doi.org/10.1016/j.matdes.2010.12.025 1

[13] P. Upadhyay and A. P. Reynolds, "Effects of Forge Axis Force and Backing Plate Thermal Diffusivity on FSW of AA6056," Materials Science and Engineering A, vol. 558, no. APRIL 2011, pp. 394-402, 2012. 1, 3, 4, 17

[14] L. Wei and T. W. Nelson, "Influence of heat input on post weld microstructure and mechanical properties of friction stir welded HSLA-65 steel," Materials Science and Engineering A, vol. 556, pp. 51-59, 2012. [Online]. Available: http://dx.doi.org/10.1016/j.msea.2012.06.057 1

[15] A. Tribe, "Study on the Fracture Toughness of Friction Stir Welded API X80," MS, Brigham Young University, 2012. 1

[16] G. Elatharasan and V. S. S. Kumar, "An experimental analysis and optimization of process parameter on friction stir welding of AA 6061-T6 aluminum alloy using RSM," Procedia Engineering, vol. 64, pp. 1227-1234, 2013. [Online]. Available: http://dx.doi.org/10.1016/j.proeng.2013.09.202 1

[17] Z. Zhang, W. Li, J. Shen, Y. Chao, J. Li, and Y.-E. Ma, "Effect of backplate diffusivity on microstructure and mechanical properties of friction stir welded joints," Materials \& Design, vol. 50, pp. 551-557, 2013. [Online]. Available: http://linkinghub.elsevier.com/retrieve/pii/ S02613069130023431

[18] P. Upadhyay and A. Reynolds, "Effect of Backing Plate Thermal Property on Friction Stir Welding of 25-mm-Thick AA6061," Metallurgical and Materials Transactions A: Physical Metallurgy and Materials Science, vol. 45A, no. April, pp. 2091-2100, 2014. 1, 4

[19] A. Fehrenbacher, N. A. Duffie, N. J. Ferrier, F. E. Pfefferkorn, and M. R. Zinn, "Effects of tool workpiece interface temperature on weld quality and quality improvements through temperature control in friction stir welding," International Journal of Advanced Manufacturing Technology, vol. 71, pp. 165-179, 2014. 1, 3, 4, 17

[20] S. B. Dickson, “An Investigation of Friction Stir Welding Parameter Effects on Post Weld Mechanical Properties,” MS, Brigham Young University, 2015. 1, 17

[21] T. W. Nelson and S. A. Rose, "Controlling hard zone formation in friction stir processed HSLA steel," Journal of Materials Processing Technology, vol. 231, pp. 66-74, 2016. [Online]. Available: http://dx.doi.org/10.1016/j.jmatprotec.2015.12.013 1, 3, 4, 16, 17

[22] Y. S. Sato, T. Onuma, K. Ikeda, and H. Kokawa, "Experimental verification of heat input during friction stir welding of Al alloy 5083," Science and Technology of Welding and Joining, vol. 21, no. 4, pp. 325-330, 2016. [Online]. Available: http://www.tandfonline.com/doi/full/10.1080/13621718.2015.1112469 1, 17 
[23] V. Manvatkar, A. De, L. E. Svensson, and T. DeBroy, "Cooling rates and peak temperatures during friction stir welding of a high-carbon steel," Scripta Materialia, vol. 94, no. August, pp. 36-39, 2015. 3

[24] A. Simar, Y. Bréchet, B. de Meester, A. Denquin, C. Gallais, and T. Pardoen, "Integrated modeling of friction stir welding of 6xxx series Al alloys: Process, microstructure and properties," Progress in Materials Science, vol. 57, no. 1, pp. 95-183, 2012. 3

[25] M. Matsushita, Y. Kitani, R. Ikeda, S. Endo, and H. Fujii, "Microstructure and Toughness of Friction Stir Weld of Thick Structural Steel," ISIJ International, vol. 52, no. 7, pp. 13351341, 2012. 3

[26] J. Allred, "An Investigation into the Mechanisms of Formation of the Hard Zone in FSW X65," MS, Brigham Young University, 2013. 3

[27] G. G. Roy, R. Nandan, and T. DebRoy, "Dimensionless correlation to estimate peak temperature during friction stir welding," Science and Technology of Welding and Joining, vol. 11, no. 5, pp. 606-608, 2006. 3

[28] D. Rosenthal, "Mathematical theory of heat distribution during welding and cutting," pp. 220-234, 1941. 3

[29] _ - "The theory of moving sources of heat and its application to metal treatments," ASME, vol. 68 , pp. 849-866, 1946. 3

[30] S. A. Rose, "The Effect of Cooling Rate of Friction Stir Welded High Strength Low Alloy Steel," MS, Brigham Young University, 2013. 6, 16

[31] T. L. Bergman, F. P. Incropera, D. P. DeWitt, and A. S. Lavine, Fundamentals of heat and mass transfer. John Wiley \& Sons, 2011. 7

[32] L. Svensson, B. Gretoft, and H. Bhadeshia, "Analysis Coolin Curves From Fusion Zone Steel Weld Deposi.Pdf," Scand. J. Metall, vol. 15, pp. 97-103, 1986. 8, 16

[33] A. Sonin, “The Physical Basis of Dimensional Analysis,” Cambridge, MA, pp. 1-56, 2001. [Online]. Available: http://link.springer.com/10.1007/978-3-642-19234-0 8

[34] A. Simar, J. Lecomte-Beckers, T. Pardoen, and B. de Meester, "Effect of boundary conditions and heat source distribution on temperature distribution in friction stir welding," Science and Technology of Welding and Joining, vol. 11, no. 2, pp. 170-177, 2006. 14

[35] A. Ozekcin, H. W. Jin, J. Y. Koo, N. V. Bangaru, R. Ayer, G. Vaughn, R. Steel, and S. Packer, "A microstructural study of friction stir welded joints of carbon steels," vol. 14, no. 4, pp. 284-288, 2004. 16

[36] A. Tribe and T. W. Nelson, "Study on the fracture toughness of friction stir welded API X80," Engineering Fracture Mechanics, vol. 150, pp. 58-69, 2015. [Online]. Available: http://dx.doi.org/10.1016/j.engfracmech.2015.10.006 16

[37] T. Nelson, S. Anderson, and D. Segrera, "Friction stir welding of X-65 steel," in TMS Annual Meeting, 2007. 16 
APPENDIX A. TOOL DRAWINGS 


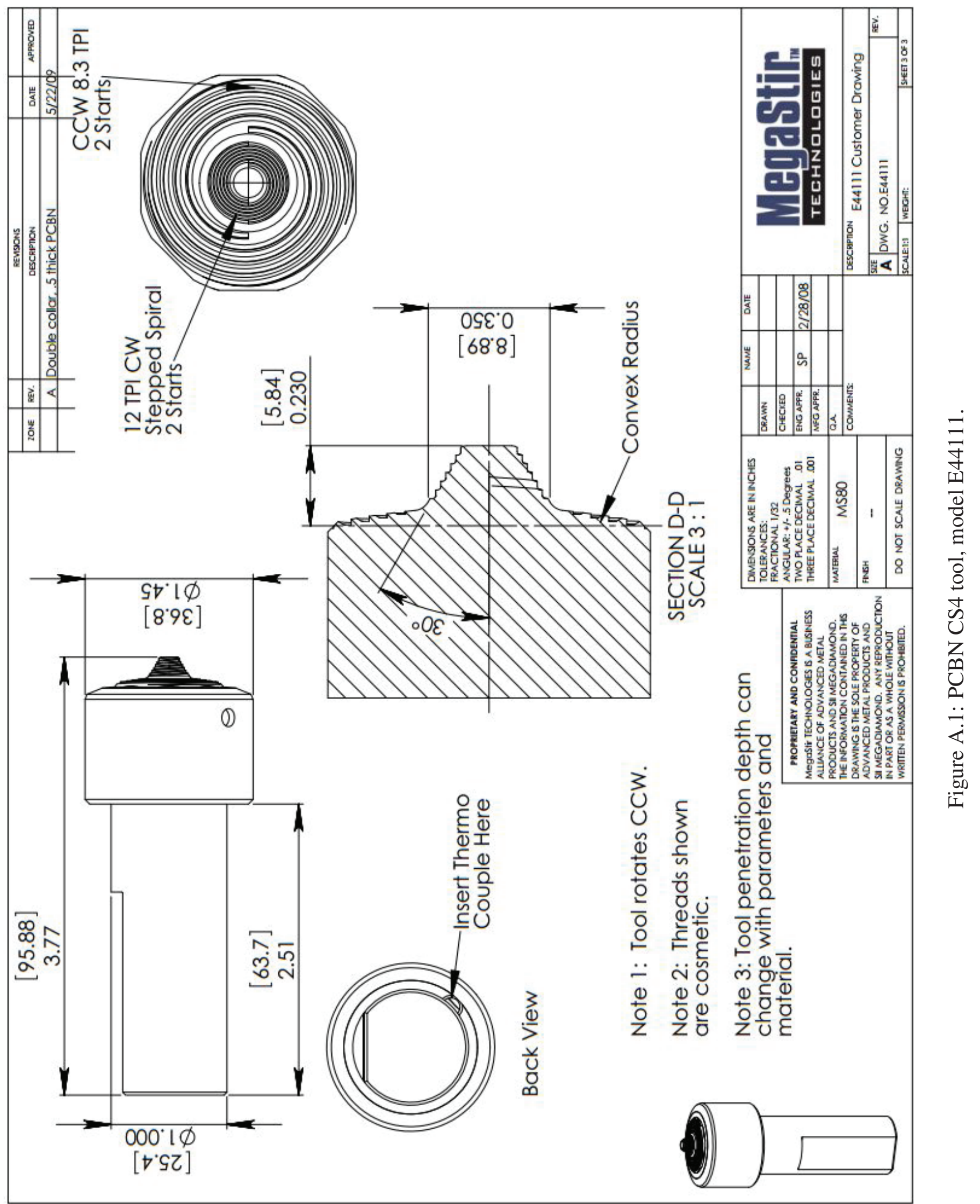




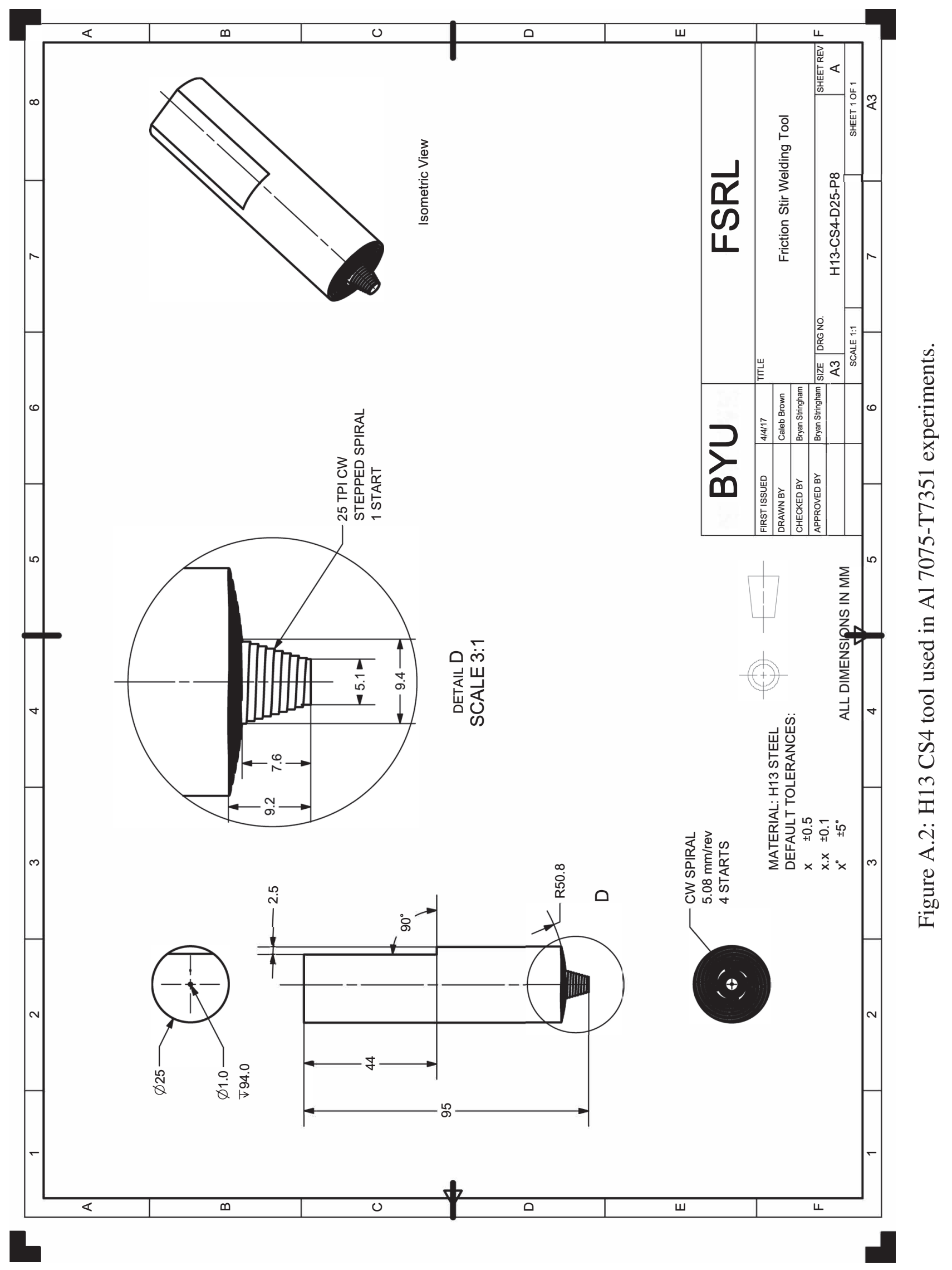




\section{APPENDIX B. TEMPERATURE VS. TIME PLOTS}

This appendix outlines how the peak temperature rise $\theta$ and cooling rate $\beta$ were calculated from the temperature versus time profiles provided by the embedded thermocouples. An example is provide for both the HSLA-65 and Al 7075 experiments.

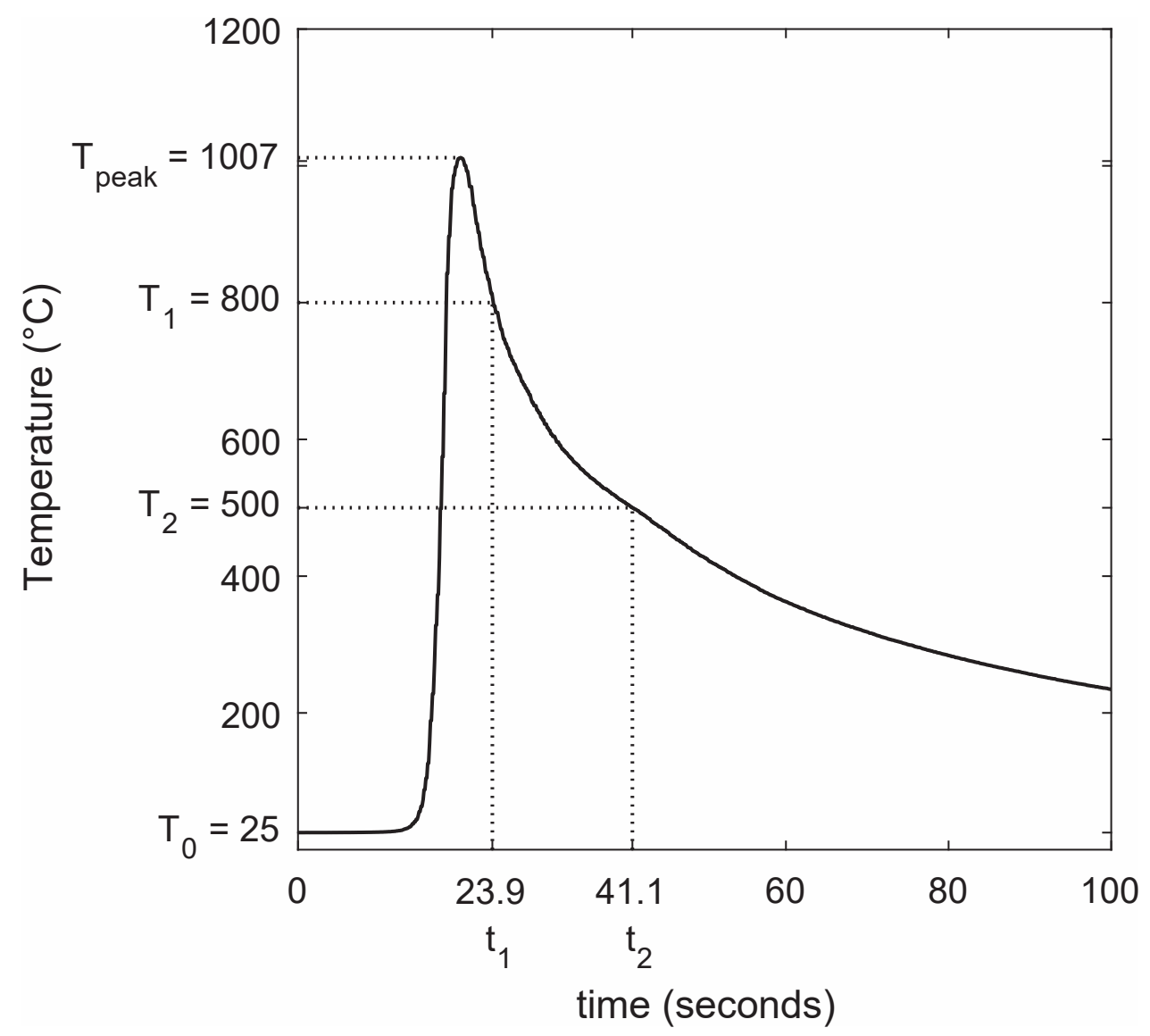

Figure B.1: Example plot for calculation of $\theta$ and $\beta$ from a temperature vs. time profile from the HSLA-65 experiment. Parameters used correspond to Data Set ID 112 as shown in Appendix C. 


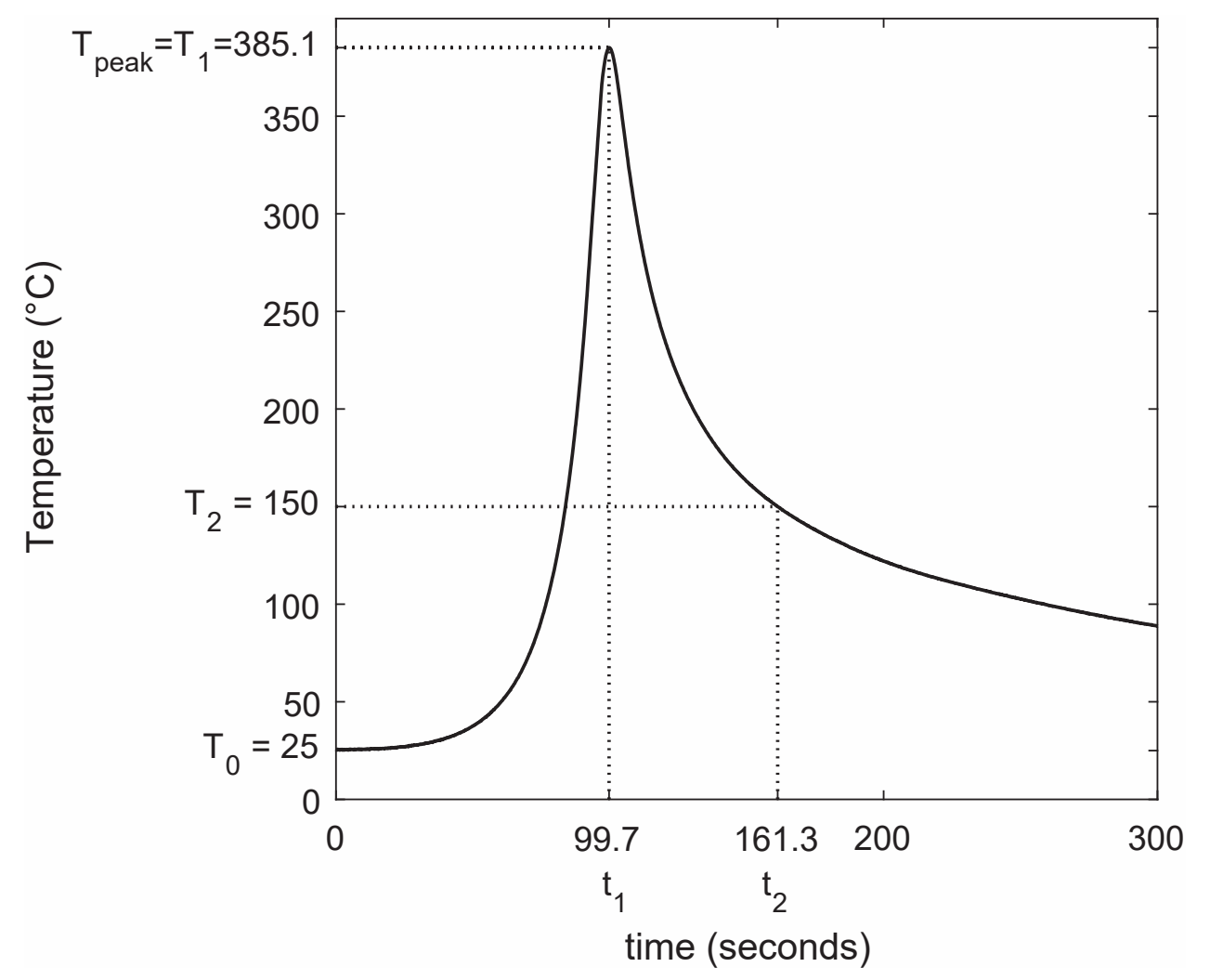

Figure B.2: Example plot for calculation of $\theta$ and $\beta$ from a temperature vs. time profile from the Al 7075 experiment. Parameters used correspond to Data Set ID 60 as shown in Appendix C. 
APPENDIX C. RAW EXPERIMENTAL PARAMETER DATA 
Table C.1: Experimental parameters and temperature data used to create the models.

\begin{tabular}{|c|c|c|c|c|c|c|c|c|c|c|c|c|c|c|c|c|c|c|}
\hline ID & $y$ & $z$ & $t_{w p}$ & $t_{b p}$ & $\alpha_{b p}$ & $k_{b p}$ & $v$ & $Q$ & $\alpha_{w p}$ & $k_{w p}$ & $T_{\text {peak }}$ & $T_{0}$ & $\theta$ & $T_{1}$ & $T_{2}$ & $t_{1}$ & $t_{2}$ & $\beta$ \\
\hline & $\mathrm{mm}$ & $\mathrm{mm}$ & $\mathrm{mm}$ & $\mathrm{mm}$ & $\frac{m m^{2}}{s}$ & $\frac{W}{m \cdot K}$ & $\frac{m m}{s}$ & W & $\frac{m m^{2}}{s}$ & $\frac{W}{m \cdot K}$ & ${ }^{\circ} \mathrm{C}$ & ${ }^{\circ} \mathrm{C}$ & ${ }^{\circ} \mathrm{C}$ & ${ }^{\circ} \mathrm{C}$ & ${ }^{\circ} \mathrm{C}$ & $s$ & $s$ & $\frac{{ }^{\circ} \mathrm{C}}{\mathrm{S}}$ \\
\hline 1 & 7.0 & 4.8 & 9.5 & 12.7 & 2.9 & 11.8 & 1.67 & 2099 & 65 & 155 & 335.6 & 25 & 310.6 & 335.6 & 150 & 37.2 & 72.8 & 5.2 \\
\hline 2 & 9.0 & 4.8 & 9.5 & 12.7 & 2.9 & 11.8 & 1.67 & 2099 & 65 & 155 & 310.8 & 25 & 285.8 & 310.8 & 150 & 37.1 & 72.1 & 4.6 \\
\hline 3 & 11.0 & 4.8 & 9.5 & 12.7 & 2.9 & 11.8 & 1.67 & 2099 & 65 & 155 & 286.9 & 25 & 261.9 & 286.9 & 150 & 37.8 & 73.0 & 3.9 \\
\hline 4 & 13.0 & 4.8 & 9.5 & 12.7 & 2.9 & 11.8 & 1.67 & 2099 & 65 & 155 & 265.7 & 25 & 240.7 & 265.7 & 150 & 40.1 & 77.1 & 3.1 \\
\hline 5 & 7.0 & 4.8 & 9.5 & 12.7 & 2.9 & 11.8 & 1.67 & 2064 & 65 & 155 & 323.9 & 25 & 298.9 & 323.9 & 150 & 40.0 & 78.2 & 4.6 \\
\hline 6 & 9.0 & 4.8 & 9.5 & 12.7 & 2.9 & 11.8 & 1.67 & 2064 & 65 & 155 & 309.3 & 25 & 284.3 & 309.3 & 150 & 40.7 & 78.9 & 4.2 \\
\hline 7 & 11.0 & 4.8 & 9.5 & 12.7 & 2.9 & 11.8 & 1.67 & 2064 & 65 & 155 & 282.8 & 25 & 257.8 & 282.8 & 150 & 37.5 & 72.4 & 3.8 \\
\hline 8 & 13.0 & 4.8 & 9.5 & 12.7 & 2.9 & 11.8 & 1.67 & 2064 & 65 & 155 & 262.5 & 25 & 237.5 & 262.5 & 150 & 36.5 & 69.7 & 3.4 \\
\hline 9 & 7.0 & 4.8 & 9.5 & 12.7 & 2.9 & 11.8 & 5.00 & 3255 & 65 & 155 & 332.0 & 25 & 307.0 & 332.0 & 150 & 17.0 & 32.7 & 11.6 \\
\hline 10 & 9.0 & 4.8 & 9.5 & 12.7 & 2.9 & 11.8 & 5.00 & 3255 & 65 & 155 & 285.1 & 25 & 260.1 & 285.1 & 150 & 17.0 & 31.9 & 9.0 \\
\hline 11 & 11.0 & 4.8 & 9.5 & 12.7 & 2.9 & 11.8 & 5.00 & 3255 & 65 & 155 & 255.9 & 25 & 230.9 & 255.9 & 150 & 16.7 & 30.5 & 7.7 \\
\hline 12 & 13.0 & 4.8 & 9.5 & 12.7 & 2.9 & 11.8 & 5.00 & 3255 & 65 & 155 & 236.2 & 25 & 211.2 & 236.2 & 150 & 15.6 & 28.3 & 6.8 \\
\hline 13 & 7.0 & 4.8 & 9.5 & 12.7 & 2.9 & 11.8 & 5.00 & 3136 & 65 & 155 & 313.5 & 25 & 288.5 & 313.5 & 150 & 15.4 & 29.2 & 11.8 \\
\hline 14 & 9.0 & 4.8 & 9.5 & 12.7 & 2.9 & 11.8 & 5.00 & 3136 & 65 & 155 & 276.0 & 25 & 251.0 & 276.0 & 150 & 16.0 & 29.8 & 9.1 \\
\hline 15 & 11.0 & 4.8 & 9.5 & 12.7 & 2.9 & 11.8 & 5.00 & 3136 & 65 & 155 & 254.0 & 25 & 229.0 & 254.0 & 150 & 16.1 & 29.6 & 7.7 \\
\hline 16 & 13.0 & 4.8 & 9.5 & 12.7 & 2.9 & 11.8 & 5.00 & 3136 & 65 & 155 & 241.4 & 25 & 216.4 & 241.4 & 150 & 15.8 & 28.8 & 7.0 \\
\hline 17 & 7.0 & 4.8 & 9.5 & 12.7 & 2.9 & 11.8 & 5.00 & 2847 & 65 & 155 & 319.8 & 25 & 294.8 & 319.8 & 150 & 14.1 & 26.8 & 13.3 \\
\hline 18 & 9.0 & 4.8 & 9.5 & 12.7 & 2.9 & 11.8 & 5.00 & 2847 & 65 & 155 & 287.3 & 25 & 262.3 & 287.3 & 150 & 14.6 & 27.5 & 10.6 \\
\hline 19 & 13.0 & 4.8 & 9.5 & 12.7 & 2.9 & 11.8 & 5.00 & 2847 & 65 & 155 & 244.9 & 25 & 219.9 & 244.9 & 150 & 14.5 & 26.6 & 7.8 \\
\hline 20 & 7.0 & 4.8 & 9.5 & 12.7 & 2.9 & 11.8 & 1.67 & 2256 & 65 & 155 & 403.4 & 25 & 378.4 & 403.4 & 150 & 53.4 & 105.6 & 4.9 \\
\hline 21 & 9.0 & 4.8 & 9.5 & 12.7 & 2.9 & 11.8 & 1.67 & 2256 & 65 & 155 & 356.0 & 25 & 331.0 & 356.0 & 150 & 53.9 & 105.9 & 4.0 \\
\hline 22 & 11.0 & 4.8 & 9.5 & 12.7 & 2.9 & 11.8 & 1.67 & 2256 & 65 & 155 & 324.0 & 25 & 299.0 & 324.0 & 150 & 51.3 & 99.9 & 3.6 \\
\hline 23 & 13.0 & 4.8 & 9.5 & 12.7 & 2.9 & 11.8 & 1.67 & 2256 & 65 & 155 & 303.6 & 25 & 278.6 & 303.6 & 150 & 49.6 & 96.1 & 3.3 \\
\hline 24 & 7.0 & 4.8 & 9.5 & 12.7 & 65.0 & 155.0 & 1.67 & 2767 & 65 & 155 & 327.8 & 25 & 302.8 & 327.8 & 150 & 25.4 & 49.6 & 7.3 \\
\hline 25 & 9.0 & 4.8 & 9.5 & 12.7 & 65.0 & 155.0 & 1.67 & 2767 & 65 & 155 & 299.1 & 25 & 274.1 & 299.1 & 150 & 29.2 & 57.2 & 5.3 \\
\hline 26 & 11.0 & 4.8 & 9.5 & 12.7 & 65.0 & 155.0 & 1.67 & 2767 & 65 & 155 & 270.9 & 25 & 245.9 & 270.9 & 150 & 28.4 & 54.7 & 4.6 \\
\hline 27 & 13.0 & 4.8 & 9.5 & 12.7 & 65.0 & 155.0 & 1.67 & 2767 & 65 & 155 & 256.6 & 25 & 231.6 & 256.6 & 150 & 27.9 & 53.2 & 4.2 \\
\hline 28 & 7.0 & 4.8 & 9.5 & 12.7 & 65.0 & 155.0 & 1.67 & 3186 & 65 & 155 & 388.3 & 25 & 363.3 & 388.3 & 150 & 37.7 & 74.9 & 6.4 \\
\hline 29 & 9.0 & 4.8 & 9.5 & 12.7 & 65.0 & 155.0 & 1.67 & 3186 & 65 & 155 & 328.6 & 25 & 303.6 & 328.6 & 150 & 38.4 & 75.1 & 4.9 \\
\hline 30 & 11.0 & 4.8 & 9.5 & 12.7 & 65.0 & 155.0 & 1.67 & 3186 & 65 & 155 & 304.2 & 25 & 279.2 & 304.2 & 150 & 36.4 & 71.3 & 4.4 \\
\hline 31 & 13.0 & 4.8 & 9.5 & 12.7 & 65.0 & 155.0 & 1.67 & 3186 & 65 & 155 & 284.0 & 25 & 259.0 & 284.0 & 150 & 34.4 & 66.9 & 4.1 \\
\hline 32 & 7.0 & 4.8 & 9.5 & 12.7 & 65.0 & 155.0 & 1.67 & 2701 & 65 & 155 & 315.0 & 25 & 290.0 & 315.0 & 150 & 29.1 & 56.8 & 6.0 \\
\hline 33 & 9.0 & 4.8 & 9.5 & 12.7 & 65.0 & 155.0 & 1.67 & 2701 & 65 & 155 & 290.6 & 25 & 265.6 & 290.6 & 150 & 29.7 & 58.2 & 4.9 \\
\hline 34 & 11.0 & 4.8 & 9.5 & 12.7 & 65.0 & 155.0 & 1.67 & 2701 & 65 & 155 & 261.7 & 25 & 236.7 & 261.7 & 150 & 30.5 & 58.8 & 3.9 \\
\hline 35 & 13.0 & 4.8 & 9.5 & 12.7 & 65.0 & 155.0 & 1.67 & 2701 & 65 & 155 & 245.4 & 25 & 220.4 & 245.4 & 150 & 29.5 & 56.8 & 3.5 \\
\hline 36 & 7.0 & 4.8 & 9.5 & 12.7 & 65.0 & 155.0 & 5.00 & 3847 & 65 & 155 & 341.8 & 25 & 316.8 & 341.8 & 150 & 10.5 & 20.2 & 19.7 \\
\hline 37 & 9.0 & 4.8 & 9.5 & 12.7 & 65.0 & 155.0 & 5.00 & 3847 & 65 & 155 & 189.0 & 25 & 164.0 & 189.0 & 150 & 5.1 & 10.0 & 7.9 \\
\hline 38 & 11.0 & 4.8 & 9.5 & 12.7 & 65.0 & 155.0 & 5.00 & 3847 & 65 & 155 & 259.9 & 25 & 234.9 & 259.9 & 150 & 11.1 & 20.3 & 12.0 \\
\hline 39 & 13.0 & 4.8 & 9.5 & 12.7 & 65.0 & 155.0 & 5.00 & 3847 & 65 & 155 & 227.6 & 25 & 202.6 & 227.6 & 150 & 11.1 & 19.5 & 9.3 \\
\hline 40 & 7.0 & 4.8 & 9.5 & 12.7 & 65.0 & 155.0 & 5.00 & 3467 & 65 & 155 & 304.0 & 25 & 279.0 & 304.0 & 150 & 9.3 & 17.3 & 19.1 \\
\hline 41 & 9.0 & 4.8 & 9.5 & 12.7 & 65.0 & 155.0 & 5.00 & 3467 & 65 & 155 & 257.0 & 25 & 232.0 & 257.0 & 150 & 9.4 & 16.9 & 14.3 \\
\hline
\end{tabular}




\begin{tabular}{|c|c|c|c|c|c|c|c|c|c|c|c|c|c|c|c|c|c|c|}
\hline ID & $y$ & $z$ & $t_{w p}$ & $t_{b p}$ & $\alpha_{b p}$ & $k_{b p}$ & $v$ & $Q$ & $\alpha_{w p}$ & $k_{w p}$ & $T_{\text {peak }}$ & $T_{0}$ & $\theta$ & $T_{1}$ & $T_{2}$ & $t_{1}$ & $t_{2}$ & $\beta$ \\
\hline 42 & 11.0 & 4.8 & 9.5 & 12.7 & 65.0 & 155.0 & 5.00 & 3467 & 65 & 155 & 236.1 & 25 & 211.1 & 236.1 & 150 & 9.2 & 16.3 & 12.0 \\
\hline 43 & 13.0 & 4.8 & 9.5 & 12.7 & 65.0 & 155.0 & 5.00 & 3467 & 65 & 155 & 216.9 & 25 & 191.9 & 216.9 & 150 & 9.2 & 16.1 & 9.8 \\
\hline 44 & 7.0 & 4.8 & 9.5 & 12.7 & 65.0 & 155.0 & 5.00 & 3907 & 65 & 155 & 353.9 & 25 & 328.9 & 353.9 & 150 & 10.2 & 19.7 & 21.5 \\
\hline 45 & 9.0 & 4.8 & 9.5 & 12.7 & 65.0 & 155.0 & 5.00 & 3907 & 65 & 155 & 300.7 & 25 & 275.7 & 300.7 & 150 & 10.4 & 19.6 & 16.4 \\
\hline 46 & 11.0 & 4.8 & 9.5 & 12.7 & 65.0 & 155.0 & 5.00 & 3907 & 65 & 155 & 267.6 & 25 & 242.6 & 267.6 & 150 & 10.2 & 18.6 & 13.9 \\
\hline 47 & 13.0 & 4.8 & 9.5 & 12.7 & 65.0 & 155.0 & 5.00 & 3907 & 65 & 155 & 236.8 & 25 & 211.8 & 236.8 & 150 & 10.8 & 19.3 & 10.2 \\
\hline 48 & 7.0 & 4.8 & 9.5 & 12.7 & 2.9 & 11.8 & 3.37 & 2523 & 65 & 155 & 321.1 & 25 & 296.1 & 321.1 & 150 & 21.8 & 41.7 & 8.6 \\
\hline 49 & 9.0 & 4.8 & 9.5 & 12.7 & 2.9 & 11.8 & 3.37 & 2523 & 65 & 155 & 304.6 & 25 & 279.6 & 304.6 & 150 & 21.5 & 41.3 & 7.8 \\
\hline 50 & 7.0 & 4.8 & 9.5 & 12.7 & 2.9 & 11.8 & 3.37 & 2523 & 65 & 155 & 321.5 & 25 & 296.5 & 321.5 & 150 & 21.2 & 41.7 & 8.4 \\
\hline 51 & 9.0 & 4.8 & 9.5 & 12.7 & 2.9 & 11.8 & 3.37 & 2523 & 65 & 155 & 297.9 & 25 & 272.9 & 297.9 & 150 & 20.6 & 40.3 & 7.5 \\
\hline 52 & 7.0 & 4.8 & 9.5 & 12.7 & 2.9 & 11.8 & 1.33 & 1994 & 65 & 155 & 361.7 & 25 & 336.7 & 361.7 & 150 & 57.0 & 115.1 & 3.6 \\
\hline 53 & 9.0 & 4.8 & 9.5 & 12.7 & 2.9 & 11.8 & 1.33 & 1994 & 65 & 155 & 336.5 & 25 & 311.5 & 336.5 & 150 & 58.6 & 117.8 & 3.2 \\
\hline 54 & 7.0 & 4.8 & 9.5 & 12.7 & 2.9 & 11.8 & 1.33 & 1994 & 65 & 155 & 363.5 & 25 & 338.5 & 363.5 & 150 & 58.1 & 119.1 & 3.5 \\
\hline 55 & 9.0 & 4.8 & 9.5 & 12.7 & 2.9 & 11.8 & 1.33 & 1994 & 65 & 155 & 329.2 & 25 & 304.2 & 329.2 & 150 & 57.8 & 118.2 & 3.0 \\
\hline 56 & 7.0 & 4.8 & 9.5 & 12.7 & 2.9 & 11.8 & 4.51 & 3383 & 65 & 155 & 386.9 & 25 & 361.9 & 386.9 & 150 & 21.3 & 41.6 & 11.6 \\
\hline 57 & 9.0 & 4.8 & 9.5 & 12.7 & 2.9 & 11.8 & 4.51 & 3383 & 65 & 155 & 338.8 & 25 & 313.8 & 338.8 & 150 & 21.5 & 41.5 & 9.4 \\
\hline 58 & 7.0 & 4.8 & 9.5 & 12.7 & 2.9 & 11.8 & 4.51 & 3383 & 65 & 155 & 391.9 & 25 & 366.9 & 391.9 & 150 & 21.2 & 42.5 & 11.4 \\
\hline 59 & 9.0 & 4.8 & 9.5 & 12.7 & 2.9 & 11.8 & 4.51 & 3383 & 65 & 155 & 333.4 & 25 & 308.4 & 333.4 & 150 & 22.7 & 44.5 & 8.4 \\
\hline 60 & 7.0 & 4.8 & 9.5 & 12.7 & 2.9 & 11.8 & 1.67 & 2505 & 65 & 155 & 385.1 & 25 & 360.1 & 385.1 & 150 & 99.7 & 161.3 & 3.8 \\
\hline 61 & 9.0 & 4.8 & 9.5 & 12.7 & 2.9 & 11.8 & 1.67 & 2505 & 65 & 155 & 356.1 & 25 & 331.1 & 356.1 & 150 & 62.2 & 124.3 & 3.3 \\
\hline 62 & 7.0 & 4.8 & 9.5 & 12.7 & 2.9 & 11.8 & 1.67 & 2505 & 65 & 155 & 371.4 & 25 & 346.4 & 371.4 & 150 & 48.7 & 101.8 & 4.2 \\
\hline 63 & 7.0 & 4.8 & 9.5 & 12.7 & 114.0 & 391.0 & 5.50 & 4128 & 65 & 155 & 312.4 & 25 & 287.4 & 312.4 & 150 & 6.1 & 11.6 & 29.8 \\
\hline 64 & 9.0 & 4.8 & 9.5 & 12.7 & 114.0 & 391.0 & 5.50 & 4128 & 65 & 155 & 250.5 & 25 & 225.5 & 250.5 & 150 & 6.9 & 12.1 & 19.3 \\
\hline 65 & 7.0 & 4.8 & 9.5 & 12.7 & 114.0 & 391.0 & 5.50 & 4128 & 65 & 155 & 286.8 & 25 & 261.8 & 286.8 & 150 & 6.0 & 11.7 & 24.1 \\
\hline 66 & 9.0 & 4.8 & 9.5 & 12.7 & 114.0 & 391.0 & 5.50 & 4128 & 65 & 155 & 265.3 & 25 & 240.3 & 265.3 & 150 & 6.1 & 11.5 & 21.1 \\
\hline 67 & 7.0 & 4.8 & 9.5 & 12.7 & 114.0 & 391.0 & 2.37 & 3555 & 65 & 155 & 322.0 & 25 & 297.0 & 322.0 & 150 & 12.8 & 26.2 & 12.9 \\
\hline 68 & 9.0 & 4.8 & 9.5 & 12.7 & 114.0 & 391.0 & 2.37 & 3555 & 65 & 155 & 295.9 & 25 & 270.9 & 295.9 & 150 & 13.1 & 26.7 & 10.7 \\
\hline 69 & 7.0 & 4.8 & 9.5 & 12.7 & 114.0 & 391.0 & 2.37 & 3555 & 65 & 155 & 319.7 & 25 & 294.7 & 319.7 & 150 & 11.0 & 24.1 & 12.9 \\
\hline 70 & 9.0 & 4.8 & 9.5 & 12.7 & 114.0 & 391.0 & 2.37 & 3555 & 65 & 155 & 290.5 & 25 & 265.5 & 290.5 & 150 & 11.6 & 25.0 & 10.5 \\
\hline 71 & 7.0 & 4.8 & 9.5 & 12.7 & 114.0 & 391.0 & 6.30 & 4728 & 65 & 155 & 295.5 & 25 & 270.5 & 295.5 & 150 & 6.2 & 11.2 & 28.8 \\
\hline 72 & 9.0 & 4.8 & 9.5 & 12.7 & 114.0 & 391.0 & 6.30 & 4728 & 65 & 155 & 262.5 & 25 & 237.5 & 262.5 & 150 & 6.3 & 11.4 & 22.3 \\
\hline 73 & 7.0 & 4.8 & 9.5 & 12.7 & 114.0 & 391.0 & 6.30 & 4728 & 65 & 155 & 299.0 & 25 & 274.0 & 299.0 & 150 & 5.9 & 11.5 & 26.9 \\
\hline 74 & 9.0 & 4.8 & 9.5 & 12.7 & 114.0 & 391.0 & 6.30 & 4728 & 65 & 155 & 263.3 & 25 & 238.3 & 263.3 & 150 & 5.9 & 11.1 & 21.9 \\
\hline 75 & 7.0 & 4.8 & 9.5 & 12.7 & 114.0 & 391.0 & 2.72 & 4086 & 65 & 155 & 338.5 & 25 & 313.5 & 338.5 & 150 & 12.5 & 25.5 & 14.5 \\
\hline 76 & 9.0 & 4.8 & 9.5 & 12.7 & 114.0 & 391.0 & 2.72 & 4086 & 65 & 155 & 306.1 & 25 & 281.1 & 306.1 & 150 & 13.0 & 26.4 & 11.7 \\
\hline 77 & 7.0 & 4.8 & 9.5 & 12.7 & 114.0 & 391.0 & 2.72 & 4086 & 65 & 155 & 336.4 & 25 & 311.4 & 336.4 & 150 & 11.3 & 24.1 & 14.5 \\
\hline 78 & 9.0 & 4.8 & 9.5 & 12.7 & 114.0 & 391.0 & 2.72 & 4086 & 65 & 155 & 300.0 & 25 & 275.0 & 300.0 & 150 & 11.7 & 24.8 & 11.5 \\
\hline 79 & 7.0 & 4.8 & 9.5 & 12.7 & 2.9 & 11.8 & 3.59 & 2693 & 65 & 155 & 340.6 & 25 & 315.6 & 340.6 & 150 & 20.7 & 41.6 & 9.1 \\
\hline 80 & 7.0 & 4.8 & 9.5 & 12.7 & 2.9 & 11.8 & 3.59 & 2693 & 65 & 155 & 344.0 & 25 & 319.0 & 344.0 & 150 & 23.6 & 45.5 & 8.9 \\
\hline 81 & 9.0 & 4.8 & 9.5 & 12.7 & 2.9 & 11.8 & 3.59 & 2693 & 65 & 155 & 307.0 & 25 & 282.0 & 307.0 & 150 & 24.0 & 46.1 & 7.1 \\
\hline 82 & 7.0 & 4.8 & 9.5 & 12.7 & 2.9 & 11.8 & 1.34 & 2012 & 65 & 155 & 367.7 & 25 & 342.7 & 367.7 & 150 & 67.0 & 131.8 & 3.4 \\
\hline 83 & 9.0 & 4.8 & 9.5 & 12.7 & 2.9 & 11.8 & 1.34 & 2012 & 65 & 155 & 311.7 & 25 & 286.7 & 311.7 & 150 & 65.1 & 126.8 & 2.6 \\
\hline
\end{tabular}




\begin{tabular}{|c|c|c|c|c|c|c|c|c|c|c|c|c|c|c|c|c|c|c|}
\hline ID & $y$ & $z$ & $t_{w p}$ & $t_{b p}$ & $\alpha_{b p}$ & $k_{b p}$ & $v$ & $Q$ & $\alpha_{w p}$ & $k_{w p}$ & $T_{\text {peak }}$ & $T_{0}$ & $\theta$ & $T_{1}$ & $T_{2}$ & $t_{1}$ & $t_{2}$ & $\beta$ \\
\hline 84 & 7.0 & 4.8 & 9.5 & 12.7 & 2.9 & 11.8 & 1.34 & 2012 & 65 & 155 & 370.8 & 25 & 345.8 & 370.8 & 150 & 60.7 & 120.0 & 3.7 \\
\hline 85 & 9.0 & 4.8 & 9.5 & 12.7 & 2.9 & 11.8 & 1.34 & 2012 & 65 & 155 & 332.6 & 25 & 307.6 & 332.6 & 150 & 59.7 & 117.0 & 3.2 \\
\hline 86 & 7.0 & 4.8 & 9.5 & 12.7 & 2.9 & 11.8 & 4.40 & 3296 & 65 & 155 & 361.8 & 25 & 336.8 & 361.8 & 150 & 24.9 & 48.4 & 9.0 \\
\hline 87 & 9.0 & 4.8 & 9.5 & 12.7 & 2.9 & 11.8 & 4.40 & 3296 & 65 & 155 & 328.7 & 25 & 303.7 & 328.7 & 150 & 24.8 & 48.2 & 7.6 \\
\hline 88 & 7.0 & 4.8 & 9.5 & 12.7 & 2.9 & 11.8 & 4.40 & 3296 & 65 & 155 & 379.5 & 25 & 354.5 & 379.5 & 150 & 24.0 & 47.0 & 9.9 \\
\hline 89 & 7.0 & 4.8 & 9.5 & 12.7 & 2.9 & 11.8 & 1.63 & 2440 & 65 & 155 & 399.9 & 25 & 374.9 & 399.9 & 150 & 67.9 & 134.4 & 3.8 \\
\hline 90 & 9.0 & 4.8 & 9.5 & 12.7 & 2.9 & 11.8 & 1.63 & 2440 & 65 & 155 & 363.3 & 25 & 338.3 & 363.3 & 150 & 67.6 & 133.8 & 3.2 \\
\hline 91 & 7.0 & 4.8 & 9.5 & 12.7 & 2.9 & 11.8 & 1.63 & 2440 & 65 & 155 & 395.2 & 25 & 370.2 & 395.2 & 150 & 58.9 & 116.6 & 4.2 \\
\hline 92 & 9.0 & 4.8 & 9.5 & 12.7 & 2.9 & 11.8 & 1.63 & 2440 & 65 & 155 & 354.6 & 25 & 329.6 & 355 & 150 & 57.3 & 112.6 & 3.7 \\
\hline 93 & 7.6 & 3.8 & 6.4 & 6.4 & 12.8 & 37.0 & 2.54 & 4547 & 8 & 30 & 856.7 & 25 & 831.7 & 800 & 500 & 13.4 & 26.1 & 23.7 \\
\hline 94 & 4.6 & 3.8 & 6.4 & 6.4 & 12.8 & 37.0 & 2.54 & 4547 & 8 & 30 & 915.2 & 25 & 890.2 & 800 & 500 & 16.5 & 31.1 & 20.6 \\
\hline 95 & 4.6 & 3.8 & 6.4 & 6.4 & 12.8 & 37.0 & 2.54 & 4547 & 8 & 30 & 946.1 & 25 & 921.1 & 800 & 500 & 17.1 & 32.2 & 19.8 \\
\hline 96 & 6.1 & 3.8 & 6.4 & 6.4 & 12.8 & 37.0 & 2.54 & 4547 & 8 & 30 & 907.0 & 25 & 882.0 & 800 & 500 & 16.1 & 30.5 & 20.9 \\
\hline 97 & 7.6 & 3.8 & 6.4 & 6.4 & 12.8 & 37.0 & 2.54 & 4547 & 8 & 30 & 839.7 & 25 & 814.7 & 800 & 500 & 14.0 & 27.4 & 22.4 \\
\hline 98 & 6.1 & 3.8 & 6.4 & 6.4 & 12.8 & 37.0 & 2.54 & 4547 & 8 & 30 & 908.3 & 25 & 883.3 & 800 & 500 & 15.8 & 30.0 & 21.1 \\
\hline 99 & 4.6 & 3.8 & 6.4 & 6.4 & 12.8 & 37.0 & 2.54 & 4547 & 8 & 30 & 936.0 & 25 & 911.0 & 800 & 500 & 17.4 & 32.5 & 19.8 \\
\hline 100 & 7.6 & 3.8 & 6.4 & 6.4 & 12.8 & 37.0 & 2.54 & 4547 & 8 & 30 & 836.2 & 25 & 811.2 & 800 & 500 & 14.6 & 28.8 & 21.2 \\
\hline 101 & 4.6 & 3.8 & 6.4 & 20.1 & 2.3 & 2.3 & 2.54 & 4502 & 8 & 30 & 1191.5 & 25 & 1166.5 & 800 & 500 & 44.0 & 76.3 & 9.3 \\
\hline 102 & 4.6 & 3.8 & 6.4 & 20.1 & 2.3 & 2.3 & 2.54 & 4502 & 8 & 30 & 1190.6 & 25 & 1165.6 & 800 & 500 & 44.5 & 77.5 & 9.1 \\
\hline 103 & 6.1 & 3.8 & 6.4 & 20.1 & 2.3 & 2.3 & 2.54 & 4502 & 8 & 30 & 1140.4 & 25 & 1115.4 & 800 & 500 & 43.3 & 76.0 & 9.2 \\
\hline 104 & 7.6 & 3.8 & 6.4 & 20.1 & 2.3 & 2.3 & 2.54 & 4502 & 8 & 30 & 1044.5 & 25 & 1019.5 & 800 & 500 & 41.4 & 74.0 & 9.2 \\
\hline 105 & 6.1 & 3.8 & 6.4 & 20.1 & 2.3 & 2.3 & 2.54 & 4502 & 8 & 30 & 1135.5 & 25 & 1110.5 & 800 & 500 & 44.1 & 77.4 & 9.0 \\
\hline 106 & 4.6 & 3.8 & 6.4 & 20.1 & 2.3 & 2.3 & 2.54 & 4502 & 8 & 30 & 1205.5 & 25 & 1180.5 & 800 & 500 & 44.9 & 77.9 & 9.1 \\
\hline 107 & 7.6 & 3.8 & 6.4 & 6.4 & 2.9 & 11.8 & 3.81 & 5296 & 8 & 30 & 856.3 & 25 & 831.3 & 800 & 500 & 12.7 & 24.8 & 24.9 \\
\hline 108 & 4.6 & 3.8 & 6.4 & 6.4 & 2.9 & 11.8 & 3.81 & 5296 & 8 & 30 & 1027.4 & 25 & 1002.4 & 800 & 500 & 15.5 & 28.9 & 22.4 \\
\hline 109 & 6.1 & 3.8 & 6.4 & 6.4 & 2.9 & 11.8 & 3.81 & 5296 & 8 & 30 & 950.0 & 25 & 925.0 & 800 & 500 & 14.3 & 26.8 & 24.0 \\
\hline 110 & 6.1 & 3.8 & 6.4 & 6.4 & 2.9 & 11.8 & 3.81 & 5296 & 8 & 30 & 957.7 & 25 & 932.7 & 800 & 500 & 15.0 & 28.2 & 22.7 \\
\hline 111 & 7.6 & 3.8 & 6.4 & 6.4 & 2.9 & 11.8 & 3.81 & 5296 & 8 & 30 & 894.2 & 25 & 869.2 & 800 & 500 & 15.9 & 30.5 & 20.5 \\
\hline 112 & 6.1 & 3.8 & 6.4 & 6.4 & 2.9 & 11.8 & 3.81 & 5296 & 8 & 30 & 1011.9 & 25 & 986.9 & 800 & 500 & 23.9 & 41.1 & 17.4 \\
\hline 113 & 4.6 & 3.8 & 6.4 & 6.4 & 2.9 & 11.8 & 3.81 & 5296 & 8 & 30 & 1168.8 & 25 & 1143.8 & 800 & 500 & 21.5 & 39.3 & 16.9 \\
\hline 114 & 7.6 & 3.8 & 6.4 & 6.4 & 2.9 & 11.8 & 3.81 & 5296 & 8 & 30 & 954.5 & 25 & 929.5 & 800 & 500 & 18.0 & 34.0 & 18.8 \\
\hline 115 & 7.6 & 3.8 & 6.4 & 6.4 & 2.9 & 11.8 & 2.54 & 4531 & 8 & 30 & 897.9 & 25 & 872.9 & 800 & 500 & 19.2 & 36.2 & 17.7 \\
\hline 116 & 4.6 & 3.8 & 6.4 & 6.4 & 2.9 & 11.8 & 2.54 & 4531 & 8 & 30 & 947.9 & 25 & 922.9 & 800 & 500 & 21.0 & 38.7 & 16.9 \\
\hline 117 & 6.1 & 3.8 & 6.4 & 6.4 & 2.9 & 11.8 & 2.54 & 4531 & 8 & 30 & 934.0 & 25 & 909.0 & 800 & 500 & 22.7 & 42.2 & 15.4 \\
\hline 118 & 4.6 & 3.8 & 6.4 & 6.4 & 2.9 & 11.8 & 2.54 & 4531 & 8 & 30 & 951.4 & 25 & 926.4 & 800 & 500 & 21.0 & 38.4 & 17.3 \\
\hline 119 & 6.1 & 3.8 & 6.4 & 6.4 & 2.9 & 11.8 & 2.54 & 4531 & 8 & 30 & 957.6 & 25 & 932.6 & 800 & 500 & 21.0 & 38.6 & 17.1 \\
\hline 120 & 7.6 & 3.8 & 6.4 & 6.4 & 2.9 & 11.8 & 2.54 & 4531 & 8 & 30 & 918.9 & 25 & 893.9 & 800 & 500 & 19.3 & 36.2 & 17.8 \\
\hline 121 & 7.6 & 3.8 & 6.4 & 6.4 & 2.9 & 11.8 & 2.54 & 4531 & 8 & 30 & 922.4 & 25 & 897.4 & 800 & 500 & 19.8 & 37.3 & 17.2 \\
\hline 122 & 7.6 & 3.8 & 6.4 & 6.4 & 12.8 & 37.0 & 1.27 & 3765 & 8 & 30 & 938.6 & 25 & 913.6 & 800 & 500 & 19.6 & 35.7 & 18.7 \\
\hline 123 & 4.6 & 3.8 & 6.4 & 6.4 & 12.8 & 37.0 & 1.27 & 3765 & 8 & 30 & 1013.4 & 25 & 988.4 & 800 & 500 & 23.7 & 42.2 & 16.2 \\
\hline 124 & 6.1 & 3.8 & 6.4 & 6.4 & 12.8 & 37.0 & 1.27 & 3765 & 8 & 30 & 994.9 & 25 & 969.9 & 800 & 500 & 23.8 & 42.8 & 15.8 \\
\hline 125 & 6.1 & 3.8 & 6.4 & 6.4 & 12.8 & 37.0 & 1.27 & 3765 & 8 & 30 & 989.3 & 25 & 964.3 & 800 & 500 & 26.8 & 48.7 & 13.7 \\
\hline
\end{tabular}




\begin{tabular}{|c|c|c|c|c|c|c|c|c|c|c|c|c|c|c|c|c|c|c|}
\hline ID & $y$ & $Z$ & $t_{w p}$ & $t_{b p}$ & $\alpha_{b p}$ & $k_{b p}$ & $v$ & $Q$ & $\alpha_{w p}$ & $k_{w p}$ & $T_{\text {peak }}$ & $T_{0}$ & $\theta$ & $T_{1}$ & $T_{2}$ & $t_{1}$ & $t_{2}$ & $\beta$ \\
\hline 126 & 6.1 & 3.8 & 6.4 & 6.4 & 12.8 & 37.0 & 1.27 & 3765 & 8 & 30 & 996.6 & 25 & 971.6 & 800 & 500 & 31.7 & 58.2 & 11.3 \\
\hline 127 & 4.6 & 3.8 & 6.4 & 6.4 & 12.8 & 37.0 & 1.27 & 3765 & 8 & 30 & 1035.7 & 25 & 1010.7 & 800 & 500 & 33.0 & 60.0 & 11.1 \\
\hline 128 & 7.6 & 3.8 & 6.4 & 6.4 & 2.9 & 11.8 & 2.54 & 4513 & 8 & 30 & 873.6 & 25 & 848.6 & 800 & 500 & 20.9 & 38.1 & 17.4 \\
\hline 129 & 4.6 & 3.8 & 6.4 & 6.4 & 2.9 & 11.8 & 2.54 & 4513 & 8 & 30 & 999.0 & 25 & 974.0 & 800 & 500 & 25.0 & 44.2 & 15.6 \\
\hline 130 & 6.1 & 3.8 & 6.4 & 6.4 & 2.9 & 11.8 & 2.54 & 4513 & 8 & 30 & 932.1 & 25 & 907.1 & 800 & 500 & 23.6 & 42.4 & 16.0 \\
\hline 131 & 4.6 & 3.8 & 6.4 & 6.4 & 2.9 & 11.8 & 2.54 & 4513 & 8 & 30 & 986.5 & 25 & 961.5 & 800 & 500 & 24.7 & 43.8 & 15.7 \\
\hline 132 & 6.1 & 3.8 & 6.4 & 6.4 & 2.9 & 11.8 & 2.54 & 4513 & 8 & 30 & 957.5 & 25 & 932.5 & 800 & 500 & 23.4 & 41.8 & 16.3 \\
\hline 133 & 7.6 & 3.8 & 6.4 & 6.4 & 2.9 & 11.8 & 2.54 & 4513 & 8 & 30 & 872.2 & 25 & 847.2 & 800 & 500 & 21.6 & 39.5 & 16.8 \\
\hline 134 & 6.1 & 3.8 & 6.4 & 6.4 & 2.9 & 11.8 & 2.54 & 4513 & 8 & 30 & 916.8 & 25 & 891.8 & 800 & 500 & 23.5 & 42.5 & 15.9 \\
\hline 135 & 4.6 & 3.8 & 6.4 & 6.4 & 2.9 & 11.8 & 2.54 & 4513 & 8 & 30 & 996.0 & 25 & 971.0 & 800 & 500 & 24.7 & 43.7 & 15.8 \\
\hline 136 & 7.6 & 3.8 & 6.4 & 6.4 & 2.9 & 11.8 & 2.54 & 4513 & 8 & 30 & 856.5 & 25 & 831.5 & 800 & 500 & 20.9 & 38.4 & 17.1 \\
\hline 137 & 7.6 & 3.8 & 6.4 & 20.1 & 2.3 & 2.3 & 1.27 & 3770 & 8 & 30 & 1173.4 & 25 & 1148.4 & 800 & 500 & 63.9 & 107.7 & 6.8 \\
\hline 138 & 4.6 & 3.8 & 6.4 & 20.1 & 2.3 & 2.3 & 1.27 & 3770 & 8 & 30 & 1326.9 & 25 & 1301.9 & 800 & 500 & 67.2 & 111.9 & 6.7 \\
\hline 139 & 6.1 & 3.8 & 6.4 & 20.1 & 2.3 & 2.3 & 1.27 & 3770 & 8 & 30 & 1223.5 & 25 & 1198.5 & 800 & 500 & 65.5 & 109.6 & 6.8 \\
\hline 140 & 4.6 & 3.8 & 6.4 & 20.1 & 2.3 & 2.3 & 1.27 & 3770 & 8 & 30 & 1238.5 & 25 & 1213.5 & 800 & 500 & 66.3 & 111.0 & 6.7 \\
\hline 141 & 6.1 & 3.8 & 6.4 & 20.1 & 2.3 & 2.3 & 1.27 & 3770 & 8 & 30 & 1189.2 & 25 & 1164.2 & 800 & 500 & 64.9 & 109.6 & 6.7 \\
\hline 142 & 7.6 & 3.8 & 6.4 & 20.1 & 2.3 & 2.3 & 1.27 & 3770 & 8 & 30 & 1159.3 & 25 & 1134.3 & 800 & 500 & 63.6 & 107.6 & 6.8 \\
\hline 143 & 6.1 & 3.8 & 6.4 & 20.1 & 2.3 & 2.3 & 1.27 & 3770 & 8 & 30 & 1213.4 & 25 & 1188.4 & 800 & 500 & 62.4 & 104.5 & 7.1 \\
\hline 144 & 4.6 & 3.8 & 6.4 & 20.1 & 2.3 & 2.3 & 1.27 & 3770 & 8 & 30 & 1237.7 & 25 & 1212.7 & 800 & 500 & 61.8 & 103.2 & 7.2 \\
\hline 145 & 7.6 & 3.8 & 6.4 & 6.4 & 2.9 & 11.8 & 1.27 & 3770 & 8 & 30 & 990.4 & 25 & 965.4 & 800 & 500 & 29.8 & 50.8 & 14.3 \\
\hline 146 & 6.1 & 3.8 & 6.4 & 6.4 & 2.9 & 11.8 & 1.27 & 3770 & 8 & 30 & 999.3 & 25 & 974.3 & 800 & 500 & 30.2 & 51.0 & 14.4 \\
\hline 147 & 7.6 & 3.8 & 6.4 & 6.4 & 2.9 & 11.8 & 1.27 & 3770 & 8 & 30 & 993.3 & 25 & 968.3 & 800 & 500 & 29.5 & 49.8 & 14.8 \\
\hline 148 & 4.6 & 3.8 & 6.4 & 20.1 & 2.3 & 2.3 & 3.81 & 5283 & 8 & 30 & 1036.4 & 25 & 1011.4 & 800 & 500 & 25.9 & 45.2 & 15.6 \\
\hline 149 & 6.1 & 3.8 & 6.4 & 20.1 & 2.3 & 2.3 & 3.81 & 5283 & 8 & 30 & 1012.2 & 25 & 987.2 & 800 & 500 & 27.4 & 48.0 & 14.5 \\
\hline 150 & 4.6 & 3.8 & 6.4 & 20.1 & 2.3 & 2.3 & 3.81 & 5283 & 8 & 30 & 1102.7 & 25 & 1077.7 & 800 & 500 & 27.3 & 47.3 & 15.0 \\
\hline 151 & 7.6 & 3.8 & 6.4 & 20.1 & 2.3 & 2.3 & 3.81 & 5283 & 8 & 30 & 916.7 & 25 & 891.7 & 800 & 500 & 22.4 & 40.0 & 17.1 \\
\hline 152 & 4.6 & 3.8 & 6.4 & 6.4 & 12.8 & 37.0 & 3.81 & 5244 & 8 & 30 & 1016.8 & 25 & 991.8 & 800 & 500 & 12.2 & 21.8 & 31.2 \\
\hline 153 & 4.6 & 3.8 & 6.4 & 6.4 & 12.8 & 37.0 & 3.81 & 5244 & 8 & 30 & 1101.1 & 25 & 1076.1 & 800 & 500 & 13.1 & 23.5 & 28.9 \\
\hline 154 & 6.1 & 3.8 & 6.4 & 6.4 & 12.8 & 37.0 & 3.81 & 5244 & 8 & 30 & 867.1 & 25 & 842.1 & 800 & 500 & 12.7 & 22.8 & 29.5 \\
\hline 155 & 7.6 & 3.8 & 6.4 & 6.4 & 12.8 & 37.0 & 3.81 & 5244 & 8 & 30 & 826.2 & 25 & 801.2 & 800 & 500 & 11.8 & 21.8 & 30.0 \\
\hline 156 & 4.6 & 3.8 & 6.4 & 6.4 & 12.8 & 37.0 & 3.81 & 5244 & 8 & 30 & 994.5 & 25 & 969.5 & 800 & 500 & 13.7 & 24.7 & 27.4 \\
\hline 157 & 7.6 & 3.8 & 6.4 & 6.4 & 12.8 & 37.0 & 3.81 & 5244 & 8 & 30 & 825.3 & 25 & 800.3 & 800 & 500 & 12.1 & 22.2 & 29.8 \\
\hline
\end{tabular}

